\section{RESEARCH ARTICLE \\ 10.1029/2018JC014760 \\ Interannual Variability of the Atlantic North Equatorial Undercurrent and Its Impact on Oxygen}

Key Points:

- Interannual variability of North

Equatorial Undercurrent in an ocean general circulation model is linked to Atlantic meridional mode

- Oxygen supply by the North

Equatorial Undercurrent toward

the eastern tropical North Atlantic

depends on the pathway of its source waters

- Different supply routes might explain discrepancies between simulated and observed oxygen supply by the North Equatorial Undercurrent

Supporting Information:

- Supporting Information S1

Correspondence to:

K. Burmeister,

kburmeister@geomar.de

Citation:

Burmeister K., Lübbecke, J. F. Brandt, P., \& Duteil, O. (2019). Interannual variability of the Atlantic North Equatorial Undercurrent and its impact on oxygen. Journal of Geophysical Research: Oceans, 124, 2348-2373. https://doi.org/10.1029/2018JC014760

Received 12 NOV 2018 Accepted 10 MAR 2019 Accepted article online 14 MAR 2019 Published online 3 APR 2019

(C)2019. American Geophysical Union. All Rights Reserved.

\author{
K. Burmeister ${ }^{1}$ iD , J. F. Lübbecke ${ }^{1,2}$ iD , P. Brandt ${ }^{1,2}$ iD , and O. Duteil ${ }^{1}$, \\ ${ }^{1}$ GEOMAR Helmholtz Centre for Ocean Research Kiel, Kiel, Germany, ${ }^{2}$ Christian-Albrechts-Universität zu Kiel, \\ Faculty of Mathematics and Natural Sciences, Kiel, Germany
}

\begin{abstract}
The North Equatorial Undercurrent (NEUC) has been suggested to act as an important oxygen supply route toward the oxygen minimum zone in the eastern tropical North Atlantic. Observational estimates of the mean NEUC strength are uncertain due to the presence of elevated mesoscale activities, and models have difficulties in simulating a realistic NEUC. Here we investigate the interannual variability of the NEUC and its impact onto oxygen based on the output of a high-resolution Ocean General Circulation Model (OGCM) and contrast the results with an unique data set of 21 ship sections along $23^{\circ} \mathrm{W}$ and a conceptual model. We find that the interannual variability of the NEUC in the OGCM is related to the Atlantic meridional mode with a stronger and more northward NEUC during negative Atlantic meridional mode phases. Discrepancies between the OGCM and observations suggest a different role of the NEUC in setting the regional oxygen distribution. In the model a stronger NEUC is associated with a weaker oxygen supply toward the east. We attribute this to a too strong recirculation between the NEUC and the northern branch of the South Equatorial Current in the OGCM. Idealized experiments with the conceptual model support the idea that the impact of NEUC variability on oxygen depends on the source water pathway. A strengthening of the NEUC supplied out of the western boundary acts to increase oxygen levels within the NEUC. A strengthening of the recirculations between NEUC and the northern branch of the South Equatorial Current results in a reduction of oxygen levels within the NEUC.
\end{abstract}

Plain Language Summary In the eastern tropical North Atlantic a zone of low-oxygen waters exists between 100 and $700 \mathrm{~m}$ due to high oxygen consumption and a weak exchange of water masses. Long-term oxygen changes in this zone have been reported with potential impacts on, for example, ecosystems including fish populations. The water masses in that region are exchanged among others via weak eastward and westward currents. The mean eastward-flowing North Equatorial Undercurrent (NEUC) transports oxygen-rich waters from the western basin into the eastern low-oxygen zone, suggesting that a stronger NEUC supplies more oxygen-rich water toward the eastern basin. In this study we investigate the year-to-year variability of the NEUC and its impact on oxygen. For our analysis, we are using ship observations and model simulations. We find some discrepancies between them that we attribute to a too strong recirculation between the NEUC and the westward-flowing current just south of it in the model. This recirculation impacts the variability of the eastward oxygen supply, as the westward current is transporting low-oxygen waters. In the model, a higher recirculation between the currents results in a stronger NEUC transporting lower-oxygen waters, a mechanism for oxygen variability that could not be conjectured from observations so far.

\section{Introduction}

The oxygen concentration in the oceans is controlled by the interaction of physical and biogeochemical processes. Oxygen is supplied to the ocean by photosynthesis or air-sea gas exchange, and it is transported into the ocean interior by advection and mixing (e.g., Brandt et al., 2015; Karstensen et al., 2008; Stramma et al., 2008). Oxygen is consumed by respiration, for example, by remineralization of sinking particles (Matear \& Hirst, 2003). Locally, advection and mixing can also act to decrease oxygen levels, depending on the background oxygen field (Brandt et al., 2010; Hahn et al., 2014).

The tropical Atlantic is characterized by a complex system of zonal currents that can transport oxygen-rich waters from the western boundary eastward toward the Eastern Tropical North Atlantic (ETNA) Oxygen 
a)

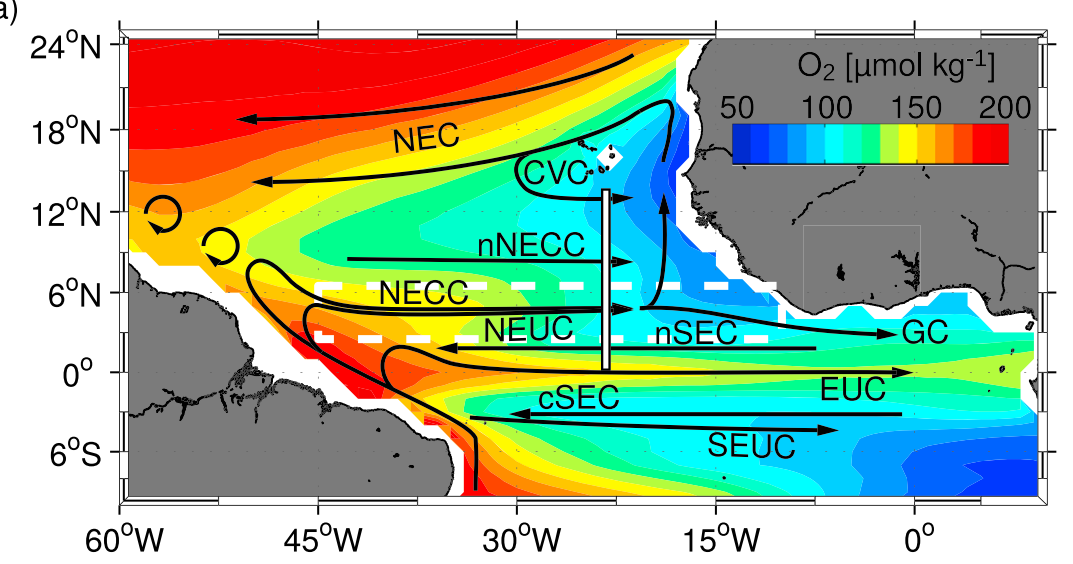

b)

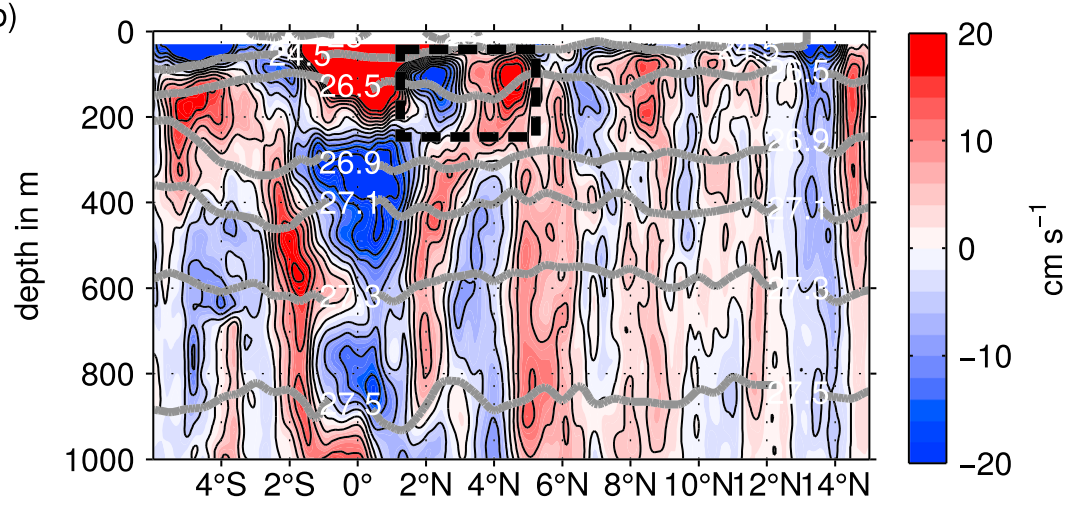

c)

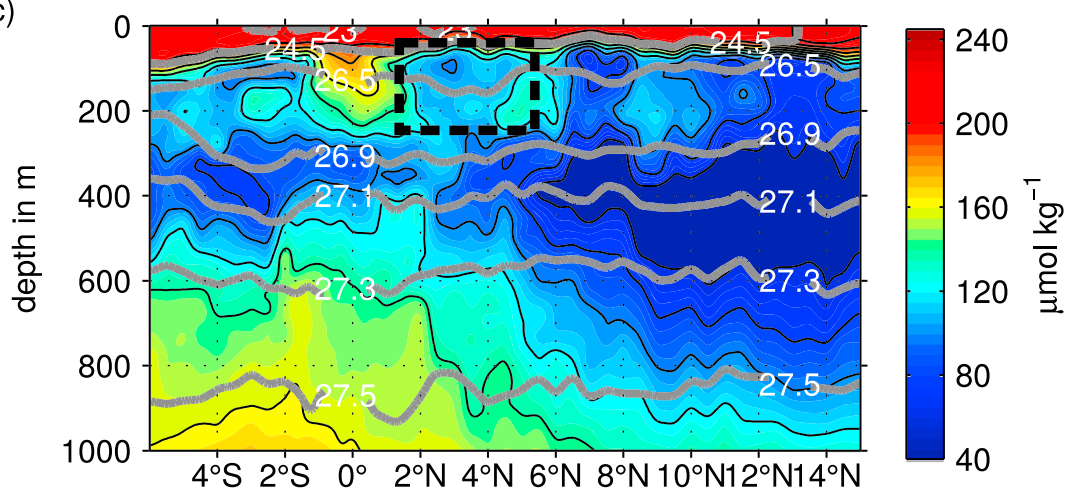

Figure 1. (a) Oxygen concentration in $\mu \mathrm{mol} / \mathrm{kg}$ (shaded colors) in the tropical Atlantic averaged between 100 and $200 \mathrm{~m}$ depth (depth range of North Equatorial Undercurrent [NEUC] core) obtained from MIMOC (Schmidtko et al., 2017). Superimposed are surface and thermocline (about upper $300 \mathrm{~m}$ ) currents (black solid arrows; adapted from Hahn et al., 2017): the North Equatorial Current (NEC), Cape Verde Current (CVC), North Equatorial Countercurrent (NECC), northern branch of the NECC (nNECC), NEUC, northern branch of the South Equatorial Current (nSEC) and central branch of the South Equatorial Current (cSEC), Equatorial Undercurrent (EUC), South Equatorial Undercurrent (SEUC), and Guinea Current (GC). The white bar denotes the $23^{\circ} \mathrm{W}$ section between $0^{\circ}$ and $14^{\circ} \mathrm{N}$. The white dashed rectangle marks the model domain of the conceptual model. (b) Zonal velocity and (c) oxygen observations along $23^{\circ} \mathrm{W}$ obtained during Meteor cruise M145 from February to March 2018. The black dashed rectangles mark the region of a potential recirculation between the nSEC and NEUC. 
Minimum Zone (OMZ) or oxygen-poor waters westward (Figure 1). Consequently, the zonal advection of oxygen-rich water masses from the western boundary by eastward-flowing ocean currents has been identified as an important ventilation process for the ETNA OMZ, especially in the upper 130 to $300 \mathrm{~m}$ (Brandt et al., 2015; Hahn et al., 2014, 2017). The most important currents are the main wind-driven ones such as the Equatorial Undercurrent (EUC), the North Equatorial Undercurrent (NEUC), and the northern branch of the North Equatorial Countercurrent (nNECC; e.g., Bourlès et al., 2002; Peña-Izquierdo et al., 2015; Schott et al., 2004). Below the wind-driven ocean circulation, the flow field in the ETNA OMZ is characterized by eddy-driven, weak latitudinal alternating zonal jets (Ascani et al., 2010; Brandt et al., 2010; Maximenko et al., 2005; Ollitrault \& Colin de Verdière, 2014; Qiu et al., 2013).

Oxygen levels in the ETNA OMZ are declining in accordance with global deoxygenation (Schmidtko et al., 2017; Stramma et al., 2008). Superimposed on this multidecadal trend are interannual to decadal variations. The identification of the mechanisms of long-term oxygen changes is challenging because of large uncertainties in the observed oxygen budget terms (Hahn et al., 2017; Oschlies et al., 2018). Furthermore, large biases in the oxygen distribution in ocean models hamper the analysis of OMZ variability (e.g. Cabré et al., 2015; Dietze \& Loeptien, 2013; Duteil et al., 2014; Oschlies et al., 2018, 2017; Stramma et al., 2012). One reason for an insufficient representation of eastern tropical OMZs in models is that state-of-the-art general circulation models have problems to realistically simulate the equatorial and off-equatorial zonal subsurface currents (Duteil et al., 2014).

Among the off-equatorial eastward subsurface current bands, the NEUC is associated with the highest oxygen levels in the eastern Tropical Atlantic basin (Figure 1). The NEUC is centered at $5^{\circ} \mathrm{N}$ (Figures 1a and 1b) and is located at depth where zonal advection plays an important role in ventilating the ETNA OMZ (Hahn et al., 2014). The western boundary regime is ventilated by oxygen-rich water masses supplied by the North Brazil Current (NBC). The EUC, NEUC, and nNECC feed from the retroflection of the NBC (Bourlès et al., 1999; Hüttl-Kabus \& Böning, 2008; Rosell-Fieschi et al., 2015; Stramma et al., 2005). The NEUC thus can supply oxygen-rich water masses from the western boundary toward the ETNA OMZ (Brandt et al., 2010; Stramma et al., 2008). Although its mean velocity is comparable to that of the nNECC, its associated oxygen maxima along $23^{\circ} \mathrm{W}$ has been observed to be several $\mu \mathrm{mol} / \mathrm{kg}$ higher (Figures $1 \mathrm{~b}$ and $1 \mathrm{c}$ ).

The underlying dynamics of the NEUC are still not fully understood. Several model studies show that the NEUC is mainly in geostrophic balance but they do not agree on its driving mechanism. Marin et al. (2000) studied the Pacific counterparts of the NEUC, the so called Tsuchiya jets or Subsurface Countercurrents, and compared their dynamics with the atmospheric zonal jets of the Hadley cell at around $30^{\circ} \mathrm{N}$. They suggest that the tropical cells are the oceanic dynamical equivalent to the Hadley cells, where the conservation of angular momentum plays a key role in explaining the zonal jets. Jochum and Malanotte-Rizzoli (2004) investigated the dynamics of the SEUC, the southern counterpart of the NEUC in the Atlantic. Their model results show that the Eliassen-Palm flux associated with the propagation of tropical instability waves (TIWs) can be one possible driver of such zonal currents. Other model studies in the Pacific suggest that the oceanic jets are pulled by the upwelling within domes in the eastern basin or by the eastern boundary upwelling (Furue et al., 2007, 2009; McCreary et al., 2002).

The NEUC is a weak and highly variable current. Its observed core velocity varies from below $0.1 \mathrm{~m} / \mathrm{s}$ (Brandt et al., 2006) to over $0.3 \mathrm{~m} / \mathrm{s}$ (Urbano et al., 2008). In ship sections the NEUC is likely to be biased by the high mesoscale activity present in the tropical Atlantic (e.g., Goes et al., 2013; Weisberg \& Weingartner, 1988). Furthermore, estimates of NEUC transport are difficult because a clear separation of the current cores of the NEUC, and North Equatorial Countercurrent (NECC) above is not possible (Figure 2a). Observational estimates range from 2.7 to $6.9 \mathrm{~Sv}$ in meridional ship sections taken between $38^{\circ} \mathrm{W}$ and $35^{\circ} \mathrm{W}$ (Bourlès et al., 1999, 2002; Schott et al., 2003, 1995; Urbano et al., 2008). Another problem is that some transport estimates from observations only cover part of the NEUC, as, for example, Brandt et al. (2006) calculated zonal current transports from a mean ship section along $26^{\circ} \mathrm{W}$. They found a transport of only $0.8 \mathrm{~Sv}$ for the eastward flow in the region of the NEUC along $26^{\circ} \mathrm{W}$ but only covered the flow south of $5^{\circ} \mathrm{N}$.

Goes et al. (2013) used a synthetic method to estimate the NEUC transport between $30^{\circ} \mathrm{W}$ and $23^{\circ} \mathrm{W}$. They combined expendable bathythermograph temperature with altimetric sea level anomalies to derive NEUC location, velocity, and transport. In the potential density layers of $24.5-26.8 \mathrm{~kg} / \mathrm{m}^{3}$ they found a NEUC trans- 


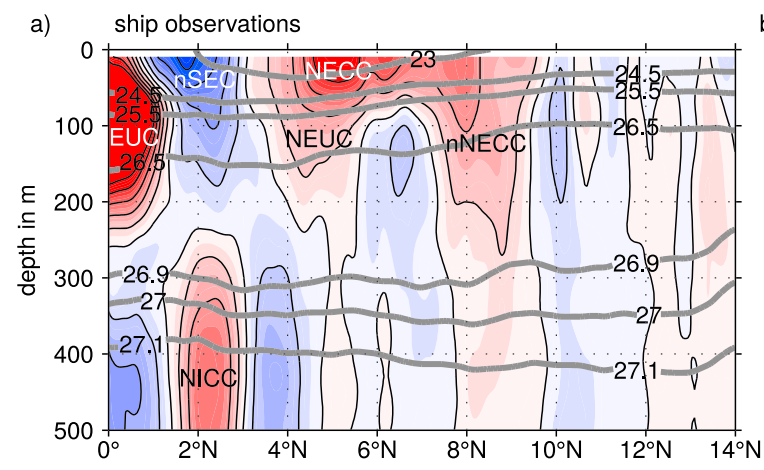

b) TRATL01 simulation
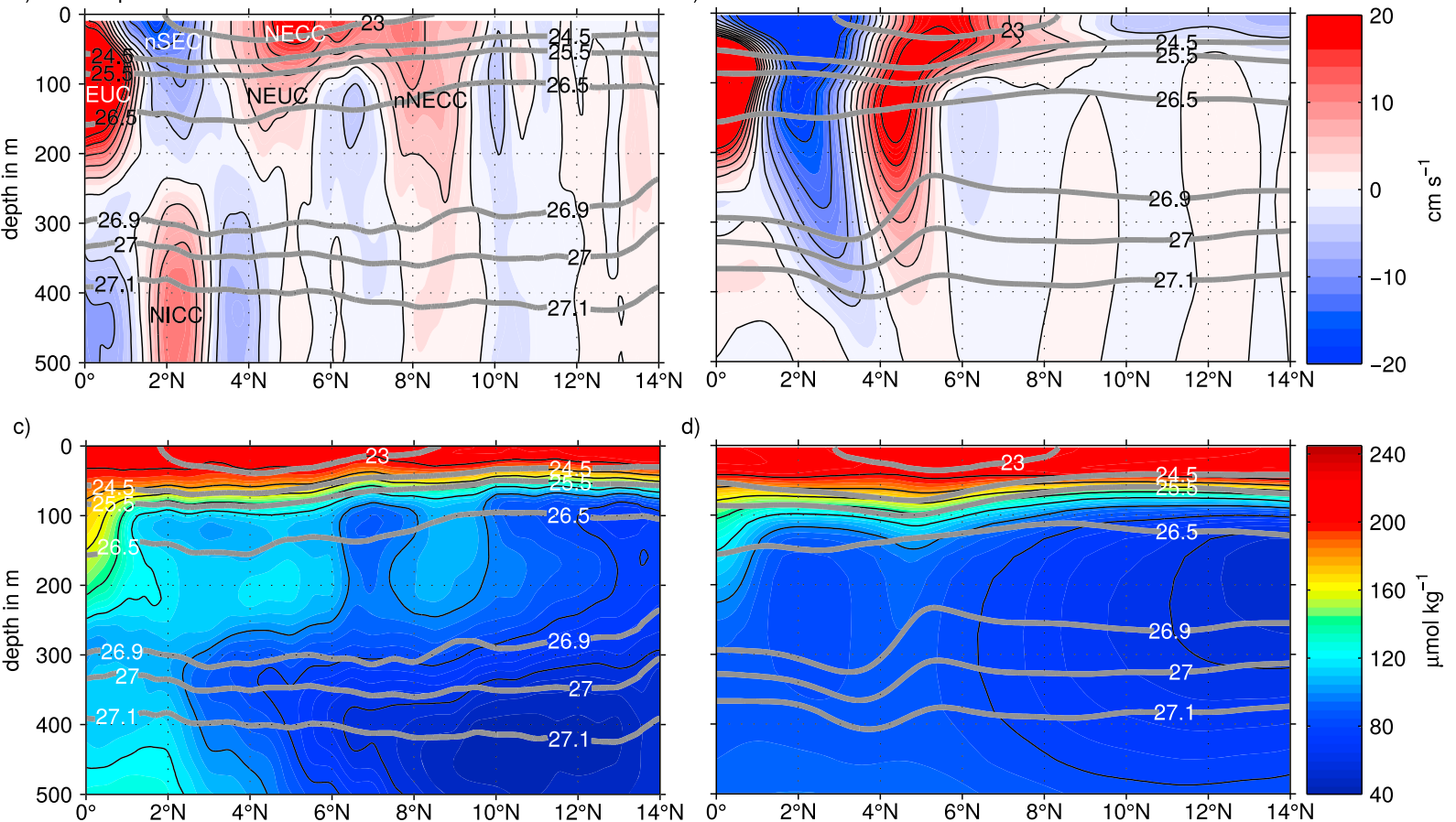

Figure 2. ( $a$ and b) Zonal velocity and ( $c$ and d) oxygen concentrations along $23^{\circ} \mathrm{W}$ from (a and c) observations and (b and d) the output of TRATL01. The observed velocity field (a) is an averaged of 21 ship sections along $23^{\circ} \mathrm{W}$ from 2002 to 2018, and the observed oxygen field (c) is an average of 11 ship section along $23^{\circ} \mathrm{W}$ from 2006 to 2018. The TRATL01 output ( $\mathrm{b}$ and d) is an averaged of the last 14 years of the model run (1994-2007) along 23 ${ }^{\circ} \mathrm{W}$. (a and b) Eastward velocities are positive (red), and westward are negative (blue). Gray contours mark neutral density surfaces $\left(\mathrm{kg} / \mathrm{m}^{3}\right)$. Currents (in a) are the Equatorial Undercurrent (EUC), the northern branch of the South Equatorial Current (nSEC), the North Equatorial Countercurrent (NECC) and its northern branch (nNECC), the North Equatorial Undercurrent (NEUC), and the North Intermediate Countercurrent (NICC).

port varying from $2.3 \mathrm{~Sv}$ during August to October to up to $5.5 \mathrm{~Sv}$ during May and June. The core position of the NEUC in the synthesis product varies between $4.5^{\circ} \mathrm{N}$ and $5.5^{\circ} \mathrm{N}$ and exhibits a semiannual cycle with minima in April and September and maxima in August and December. Their estimated NEUC core velocities were highest in June (above $0.3 \mathrm{~m} / \mathrm{s}$ ) and lowest during boreal fall (below $0.2 \mathrm{~m} / \mathrm{s}$ ). In a model study, Hüttl-Kabus and Böning (2008) found a clear seasonal cycle of the NEUC at $35^{\circ} \mathrm{W}$ and $23^{\circ} \mathrm{W}$ with maximum NEUC transports (4.5-7.0 Sv) between May and June, and minimum transports (1.2-4.2 Sv) between September and October. They found a westward propagation of the seasonal cycle consistent with annual Rossby wave patterns (Böning \& Kröger, 2005; Brandt \& Eden, 2005; Thierry et al., 2004).

In ship sections the NEUC shows no clear seasonal cycle. Four transport estimates exist between $35^{\circ} \mathrm{W}$ and $38^{\circ} \mathrm{W}$ during boreal spring from 1993 to 1996 (Bourlès et al., 1999; Schott et al., 1995). In the same depth range as in Goes et al. (2013) and Hüttl-Kabus and Böning (2008), they vary from 1.6 to 3.6 Sv, and the NEUC position varies between $3.5^{\circ} \mathrm{N}$ and $5.5^{\circ} \mathrm{N}$. For boreal fall there is one NEUC transport estimate of $2.5 \mathrm{~Sv}$ between $4^{\circ} \mathrm{N}$ and $6^{\circ} \mathrm{N}$ (Bourlès et al., 1999). Note that especially during boreal summer and fall as well as in the mean ship sections, the NEUC and the NECC are difficult to distinguish (Brandt et al., 2006; Bourlès et al., 1999, 2002; Schott et al., 2003; Urbano et al., 2008). As the NEUC is likely to be obscured by the high mesoscale activity (Goes et al., 2013; Weisberg \& Weingartner, 1988) and interannual variability (Goes et al., 2013; Hüttl-Kabus \& Böning, 2008), the mean is uncertain, and the seasonal cycle cannot be estimated reliably from ship sections.

Only few studies have investigated the interannual variability of the NEUC. In a model study Hüttl-Kabus and Böning (2008) estimated an interannual variability of the seasonal cycle of $2 \mathrm{~Sv}$, which is almost as strong as the amplitude of the seasonal cycle (3 Sv). The results of Goes et al. (2013) indicate an anticorrelation between NEUC transport variability and the Atlantic meridional mode (AMM). The AMM is characterized by a meridional interhemispheric gradient of sea surface temperature (SST) in the tropical Atlantic centered around $5^{\circ} \mathrm{N}$ (Nobre \& Shukla, 1996). Important drivers of the AMM are wind-induced evaporation and the wind-evaporation-SST feedback (Carton et al., 1996; Chang et al., 2000). Initially high SSTs in the northern 
tropical Atlantic lead to a low sea level pressure anomaly, which causes cross-equatorial sea surface wind anomalies blowing from the Southern toward the Northern Hemisphere. This strengthens the southeast trade winds, increases evaporation, and leads to a negative heat flux anomaly into the ocean in the Southern Hemisphere, that is, a reduction of SST here. In the Northern Hemisphere the trade winds are weakened by the anomalous atmosphere flow, and less evaporation associated with a positive heat flux anomaly into the ocean amplifies the initial warming here. This is referred to a positive AMM. The negative AMM is associated with a warming and a cooling in the Southern and Northern Hemisphere, respectively.

Goes et al. (2013) hypothesized that changes in the meridional density gradient driven by the AMM are a possible mechanism that can drive NEUC variability. They highlight the inverse SST anomalies in the Guinea Dome region and in the equatorial Atlantic associated with the AMM. This can alter the north-south density gradient in the NEUC region and strengthen (negative AMM, increased density gradient) or weaken (positive AMM, decreased density gradient) the NEUC core (Furue et al., 2007; Goes et al., 2013; McCreary et al., 2002).

In summary, the interannual variability of the NEUC and its potential drivers are still not fully understood. As the NEUC is suggested to act as an important oxygen supply route toward the ETNA OMZ, it is crucial to understand possible mechanisms by which the NEUC variability impacts the oceanic oxygen distribution. As observations are still too sparse, we will use a state-of-the-art ocean general circulation model (OGCM) in combination with a conceptual model to study these mechanisms.

In this study we investigate the interannual variability of the NEUC and the associated oxygen response in a state-of-the-art OGCM and a conceptual model. The study aims to improve (1) the understanding of oceanic processes that impact the mean distribution and interannual variability of dissolved oxygen in the NEUC region and (2) the understanding of discrepancies between simulated and observed NEUC variability and associated oxygen changes. For our analysis we are using the output of the high-resolution OGCM TRATL01 (Duteil et al., 2014) in combination with an unique data set of 21 ship section along $23^{\circ} \mathrm{W}$ from 2002 to 2018. We utilize an algorithm developed by Hsin and Qiu (2012) to estimate the NEUC position and intensity in both the observational data and the output of TRATL01. To better understand the contradicting results between the observations and the TRATL01 output, we extend our analysis with a conceptual model simulating an eastward current and its westward return flow with an oxygen source at the western boundary following Brandt et al. (2010).

\section{Data and Methods}

\subsection{Observations}

Velocity data of 21 ship sections along $23^{\circ} \mathrm{W}$ obtained from 2002 to 2018 are used. For 12 and 11 of these sections also hydrographic and oxygen data are available, respectively. A detailed overview of the cruises is shown in Table 1 . All ship sections cover at least the upper $400 \mathrm{~m}$ between $0^{\circ}$ and $8^{\circ} \mathrm{N}$.

Velocity data are acquired by vessel-mounted and lowered acoustic Doppler current profilers (ADCPs). Vessel-mounted ADCPs (vm-ADCPs) are continuously recording velocities throughout the section. The accuracy of 1-hr averaged vm-ADCP data is better than $2-4 \mathrm{~cm} / \mathrm{s}$ (Fischer et al., 2003). Lowered ADCPs (l-ADCPs) are attached in pairs of upward and downward looking instruments to a CTD (conductivity-temperature-depth) rosette and record velocities during CTD casts typically performed on a uniform latitude grid with half-degree resolution. This enables velocity measurements throughout the whole water column. The accuracy of full-depth l-ADCP velocity profiles is better than $5 \mathrm{~cm} / \mathrm{s}$ (Visbeck, 2002). Hydrographic and oxygen data are obtained during CTD casts. The data accuracy for a single research cruise are generally assumed to be better than $0.002{ }^{\circ} \mathrm{C}, 0.002$, and $2 \mu \mathrm{mol} / \mathrm{kg}$ for temperature, salinity, and dissolved oxygen, respectively (Hahn et al., 2017). The final ship sections and mean sections along $23^{\circ} \mathrm{W}$ are obtained from the observational data as described in Brandt et al. (2010). First all velocity data are merged accounting for their different accuracy and resolution. Then the velocity, hydrographic, and oxygen data are mapped on a regular grid $\left(0.05^{\circ}\right.$ latitude $\left.\times 10 \mathrm{~m}\right)$ using a Gaussian interpolation scheme. All data are averaged at each grid point to derive the mean sections, which are smoothed by a Gaussian filter (horizontal and vertical influence [cutoff] radii: $0.05^{\circ}\left[0.1^{\circ}\right]$ latitude, and $10 \mathrm{~m}[20 \mathrm{~m}]$, respectively). For the mean velocity, temperature, salinity, and oxygen section, the standard error in the NEUC region (100 to $300 \mathrm{~m}$ depth, $3^{\circ}-6.5^{\circ} \mathrm{N}$ ) are $1.4 \mathrm{~cm} / \mathrm{s}, 0.12^{\circ} \mathrm{C}, 0.01$, and $3.4 \mu \mathrm{mol} / \mathrm{kg}$, respectively. 
Table 1

Ship Sections Along $23^{\circ} \mathrm{W}$ From 2002 to 2018

\begin{tabular}{|c|c|c|c|c|c|c|}
\hline Cruise & Expocode & Date & Longitude & Latitude & $\mathrm{O}_{2}$ & CTD \\
\hline Meteor 55 & 06MT20021013 & 2002 Oct & $24^{\circ} \mathrm{W}$ & $010^{\circ} \mathrm{N}$ & No & No \\
\hline Ronald H. Brown & 33RO20030619 & 2003 Aug & $27^{\circ} \mathrm{W}$ & $-6-10^{\circ} \mathrm{N}$ & No & No \\
\hline Ronald H. Brown & 33RO20060527 & 2006 Jun & $23^{\circ} \mathrm{W}$ & $-5-13.5^{\circ} \mathrm{N}$ & Yes & Yes \\
\hline Meteor 68/2 & 06M320060606 & 2006 Jun & $23^{\circ} \mathrm{W}$ & $-4-14^{\circ} \mathrm{N}$ & Yes & Yes \\
\hline Ronald H. Brown & 33RO20060622 & 2006 Jun & $23^{\circ} \mathrm{W}$ & $-5-14^{\circ} \mathrm{N}$ & Yes & Yes \\
\hline L'Atalante & $35 \mathrm{~A} 320080223$ & $2008 \mathrm{Mar}$ & $23^{\circ} \mathrm{W}$ & $-2-14^{\circ} \mathrm{N}$ & Yes & Yes \\
\hline L'Atalante & $35 \mathrm{~A} 320080223$ & 2008 Mar & $23^{\circ} \mathrm{W}$ & $-2-14^{\circ} \mathrm{N}$ & No & No \\
\hline Ronald H. Brown PNE09 & 33RO20090711 & $2009 \mathrm{Jul}$ & $23^{\circ} \mathrm{W}$ & $0-14^{\circ} \mathrm{N}$ & No & No \\
\hline \multirow[t]{2}{*}{ Meteor $80 / 1$} & 06M320091026 & 2009 Nov & $23^{\circ} \mathrm{W}$ & $-6-14^{\circ} \mathrm{N}$ & Yes & Yes \\
\hline & & 2009 Nov & $23^{\circ} \mathrm{W}$ & $-6-14^{\circ} \mathrm{N}$ & No & No \\
\hline Meteor 81/1 & 06M320100204 & $2010 \mathrm{Feb}$ & $22^{\circ} \mathrm{W}$ & $-6-13^{\circ} \mathrm{N}$ & No & No \\
\hline Ronald H. Brown PNE10 & 33RO20100426 & 2010 May & $23^{\circ} \mathrm{W}$ & $0-14^{\circ} \mathrm{N}$ & No & Yes \\
\hline Maria S. Merian 18/2 & 06MM20110511 & 2011 May & $23^{\circ} \mathrm{W}$ & $0-14^{\circ} \mathrm{N}$ & No & No \\
\hline Ronald H. Brown PNE11 & 33RO20110721 & 2011 Aug & $23^{\circ} \mathrm{W}$ & $0-14^{\circ} \mathrm{N}$ & No & No \\
\hline \multirow[t]{2}{*}{ Maria S. Merian 22} & 06MM20121024 & 2012 Nov & $23^{\circ} \mathrm{W}$ & $-6-8^{\circ} \mathrm{N}$ & Yes & Yes \\
\hline & & 2012 Nov & $23^{\circ} \mathrm{W}$ & $0-14^{\circ} \mathrm{N}$ & No & No \\
\hline Meteor 106 & 06M320140419 & 2014 May & $23^{\circ} \mathrm{W}$ & $-6-14^{\circ} \mathrm{N}$ & Yes & Yes \\
\hline Polarstern PS88.2 & 06AQ20141102 & 2014 Nov & $23^{\circ} \mathrm{W}$ & $-2-14^{\circ} \mathrm{N}$ & Yes & Yes \\
\hline Meteor 119 & 06M320150908 & 2015 Sep & $23^{\circ} \mathrm{W}$ & $-5.5-14^{\circ} \mathrm{N}$ & Yes & Yes \\
\hline Meteor 130 & 06M320160828 & 2016 Aug & $23^{\circ} \mathrm{W}$ & $-6-14^{\circ} \mathrm{N}$ & Yes & Yes \\
\hline Meteor 145 & 06M320180213 & $2018 \mathrm{Feb}$ & $23^{\circ} \mathrm{W}$ & $-6-14^{\circ} \mathrm{N}$ & Yes & Yes \\
\hline
\end{tabular}

Note. $\mathrm{CTD}=$ conductivity-temperature-depth. All sections cover at least the upper $400 \mathrm{~m}$ from $0^{\circ} \mathrm{N}$ to $8^{\circ} \mathrm{N}$. For all sections acoustic Doppler current profiler data are available. Sections including oxygen $\left(\mathrm{O}_{2}\right)$ or hydrography (CTD) measurements are marked accordingly.

\subsection{High-Resolution Global Ocean Circulation Model TRATL01}

We are using the output of the global ocean circulation model TRATL01, in which a $1 / 10^{\circ}$ nest covering the tropical Atlantic from $30^{\circ} \mathrm{S}$ to $30^{\circ} \mathrm{N}$ is embedded into a global $1 / 2^{\circ}$ model (Duteil et al., 2014). TRATL01 reproduces the tropical zonal jets more realistically compared to a coarser resolution model, resulting in an improved representation of the low oxygenated regions in the ETNA (Duteil et al., 2014). The model is based on the Nucleus for European Modeling of the Ocean (NEMO) v3.1 code (Madec, 2008). The thickness of its 46 vertical levels increases from $6 \mathrm{~m}$ at the surface to $250 \mathrm{~m}$ at depth. The model is forced with momentum, heat, and freshwater fluxes from the Coordinated Ocean-Ice Reference Experiments (CORE) v2 data set for the time period from 1948 to 2007 (Griffies et al., 2009). A simple biogeochemical model is coupled with the global ocean circulation model. The biogeochemical model contains six compartments (dissolved oxygen, phosphate, phytoplankton, zooplankton, particulate, and dissolved organic matter). The parameter set (e.g., phytoplankton growth rate, mortality, and grazing) has been optimized to realistically reproduce the oxygen and phosphate distribution in a global model (Kriest et al., 2010).

We are analyzing the monthly mean model output from 1958 to 2007. In TRATL01, oxygen concentrations in the NEUC region ( 100 to $300 \mathrm{~m}$ depth, $3^{\circ}-6.5^{\circ} \mathrm{N}, 45^{\circ}-15^{\circ} \mathrm{W}$ ) are drifting on average by $-0.5 \mu \mathrm{mol} \cdot \mathrm{kg}^{-1} \cdot \mathrm{year}^{-1}$ from 1958 to 2007, reaching an equilibrium state would take several hundred years. The spurious drift is very strong in the first 30 years (144\% of the averaged drift). Therefore, the analysis of the oxygen variability is restricted to the period 1990-2007 where the drift is only $11 \%$ of the averaged drift. For the mean velocity, temperature, salinity, and oxygen section along $23^{\circ} \mathrm{W}$ from 1990 to 2007 in TRATL01, the standard errors in the NEUC region (100 to $300 \mathrm{~m}$ depth, $3^{\circ}-6.5^{\circ} \mathrm{N}$ ) are $1.02 \mathrm{~cm} / \mathrm{s}, 0.09^{\circ} \mathrm{C}, 0.01$, and $0.81 \mu \mathrm{mol} / \mathrm{kg}$, respectively. 


\subsection{NEUC Characterization}

For both TRATL01 and the observational data, we calculate the central position $Y_{C M}$ and along-pathway intensity INT of the NEUC using the algorithm of Hsin and Qiu (2012).

$$
\begin{gathered}
Y_{C M}(x, t)=\frac{\int_{Z_{l}}^{Z_{u}} \int_{Y_{S}}^{Y_{N}} y u(x, y, z, t) d y d z}{\int_{Z_{l}}^{Z_{u}} \int_{Y_{S}}^{Y_{N}} u(x, y, z, t) d y d z}, \\
I N T(x, t)=\int_{Z_{l}}^{Z_{u}} \int_{Y_{C M}-W}^{Y_{C M}+W} u(x, y, z, t) d y d z,
\end{gathered}
$$

where $y$ is latitude, $x$ is longitude, $u$ is zonal velocity, $z$ is depth, $t$ is time, $Z_{u}\left(Z_{l}\right)$ is upper (lower) boundary of the flow, $Y_{N}\left(Y_{S}\right)$ is northern (southern) limit of the flow, and $W$ is the half mean width of the flow.

The advantage of this method is that the transport calculation follows the current core avoiding artifacts if the current is meridionally migrating. In TRATL01 we choose the depth of the $24.5 \mathrm{~kg} / \mathrm{m}^{3}$ neutral density surface as the upper boundary $Z_{u}$. This density surface represents the upper boundary of the NEUC during boreal winter, the season when the NECC is weak or not present and the NEUC can clearly be separated from the near-surface flow. The lower boundary $Z_{l}$ is the depth of the $27.0 \mathrm{~kg} / \mathrm{m}^{3}$ neutral density surface. A half mean width $W$ of $2^{\circ}$ is chosen for the NEUC. The integration is performed between $42^{\circ} \mathrm{W}$ and $15^{\circ} \mathrm{W}$. For the integration of the observational data, slightly different boundary conditions are chosen to be consistent with the hydrographical conditions of the region. $Z_{u}$ is the depth of the $24.5 \mathrm{~kg} / \mathrm{m}^{3}$, and $Z_{l}$ the depth of the $26.9 \mathrm{~kg} / \mathrm{m}^{3}$ neutral density surface. The southern boundary is chosen as $Y_{C M}-1.5^{\circ}$, and the northern boundary is $Y_{C M}+1.0^{\circ}$. Note if no hydrographic measurements are available for a single ship section, the neutral density field derived from the mean hydrographic section is used.

\subsection{Conceptual Model}

We are using a conceptual model to investigate the oxygen response to specific circulation processes within the NEUC. It is based on the advection-diffusion model described in Brandt et al. (2010), which simulates an eastward current and its westward return flows with an oxygen source at the western boundary. The model equation (equation (3)) used for all simulations throughout the study reads

$$
\frac{\partial C}{\partial t}=-a O U R-u \frac{\partial C}{\partial x}-v \frac{\partial C}{\partial y}+k_{x} \frac{\partial^{2} C}{\partial x^{2}}+k_{y} \frac{\partial^{2} C}{\partial y^{2}}+k_{y} F_{c o r r} \frac{\partial^{2} C_{b g}}{\partial y^{2}}+k_{z} F_{c o r r} \frac{\partial^{2} C_{b g}}{\partial z^{2}},
$$

where $C$ is the dissolved oxygen concentration; $a O U R$ the oxygen consumption; $u$ and $v$ the zonal and meridional velocity components, respectively; $k_{x}$ and $k_{y}$ the zonal and meridional eddy diffusivities, respectively; $k_{z}$ the vertical eddy diffusivity; $C_{b g}$ the constant large-scale background oxygen distribution; and $F_{\text {corr }}$ a correction factor to the background oxygen curvature depending on the simulated oxygen concentration described below. The oxygen concentration at the western boundary $C_{0}$ is held constant at $147 \mu \mathrm{mol} / \mathrm{kg}$, which is the mean oxygen concentration at the western boundary of the NEUC $\left(\gamma_{n}=26.5 \mathrm{~kg} / \mathrm{m}^{3}\right.$, $2.5^{\circ}-6.5^{\circ} \mathrm{N}, 43^{\circ}-47^{\circ} \mathrm{W}$ ) derived from the MIMOC climatology (Schmidtko et al., 2017). In the model, the following seven terms on the right-hand side determine the oxygen tendency on the left-hand side (from left to right): (1) oxygen consumption, (2) zonal advection, (3) meridional advection, (4) zonal eddy diffusion, (5) meridional eddy diffusion associated with eastward and westward jets, and (6) meridional and (7) vertical eddy diffusion associated with the large-scale oxygen distribution in the upper $300 \mathrm{~m}$ between $0^{\circ} \mathrm{N}$ and $10^{\circ} \mathrm{N}$.

The model parameters are tuned to fit a region covering an eastward current and its return flow between $2.5^{\circ} \mathrm{N}(y=0)$ and $6.5^{\circ} \mathrm{N}\left(y=l_{y}\right)$ from $45^{\circ} \mathrm{W}(x=0)$ to $10^{\circ} \mathrm{W}\left(x=l_{x}\right)$. For the idealized background flow field we use the same definition of the streamfunction as described in Brandt et al. (2010) and adjust it to fit the observations in the NEUC regions.

$$
u=u_{0} \frac{l_{x}-x}{l_{x}} \cos \left(\frac{2 \pi y}{l_{y}}\right), \quad v=-\frac{u_{0}}{2 \pi} \frac{l_{y}}{l_{x}} \sin \left(\frac{2 \pi y}{l_{y}}\right),
$$

where $u_{0}$ is the amplitude of the zonal jets at the western boundary. For steady state solutions, $u_{0}$ is held constant, whereas for some interannual variability simulations $u_{0}$ is multiplied with a time varying sinusoid. 
Two modifications of the Brandt et al. (2010) model are realized. (i) We are using a constant, depth-dependent oxygen consumption according to Karstensen et al. (2008); (ii) we modify the model parameters to correspond to the conditions of the NEUC region.

(i) The oxygen consumption used here is defined as the logarithmic function as given in Karstensen et al. (2008):

$$
a O U R=c_{1}+c_{2} \cdot e^{-\lambda z}
$$

$\left(c_{1}=-0.5, c_{2}=12, \lambda=0.0021\right)$. To avoid negative oxygen values, the consumption term is switched off when oxygen concentrations fall below $2 \mu \mathrm{mol} / \mathrm{kg}$.

(ii) We fit our parameters to the $26.5 \mathrm{~kg} / \mathrm{m}^{3}$ neutral density surface, which corresponds to the core depth of the NEUC. A meridional and vertical eddy diffusion associated with the large-scale oxygen distribution is derived from observations, as well as a correction factor for the background meridional diffusion as described below.

The NEUC is located in a region where oxygen concentrations are increasing equatorward and decreasing poleward. Also, in the vertical profile, oxygen concentrations are changing within the NEUC. To account for this background oxygen field, we estimate a meridional and vertical eddy diffusion associated with the meridional and vertical oxygen curvature in the observation at $23^{\circ} \mathrm{W}$. We obtain the meridional eddy diffusion associated with the meridional oxygen distribution $\left(\frac{\partial^{2} C_{b g}}{\partial y^{2}}=D_{y}\right)$ similar to Brandt et al. (2010). We apply a second-order fit to the observed oxygen distribution along the $26.5 \mathrm{~kg} / \mathrm{m}^{3}$ neutral density surface at $23^{\circ} \mathrm{W}$ between $0^{\circ}$ and $10^{\circ} \mathrm{N}$, which results in $D_{y}=1.55 \cdot 10^{-10} \mu \mathrm{mol} \cdot \mathrm{kg}^{-1} \cdot \mathrm{m}^{-2}$. The vertical eddy diffusion associated with the vertical background oxygen distribution $\left(\frac{\partial^{2} C_{b g}}{\partial z^{2}}=D_{z}\right)$ is estimated by calculating the curvature of the mean vertical oxygen profile between $2.5^{\circ} \mathrm{N}$ and $6.5^{\circ} \mathrm{N}$ at $23^{\circ} \mathrm{W}$. We obtain $D_{z}=0.0112 \mu \mathrm{mol} \cdot \mathrm{kg}^{-1} \cdot \mathrm{m}^{-2}$ for $130 \mathrm{~m}$, which corresponds to the depth of the $26.5 \mathrm{~kg} / \mathrm{m}^{3}$ neutral density surface.

The correction factor for the background meridional diffusion is given as follows:

$$
F_{\text {corr }}=\frac{C_{0}-\overline{C_{23 W}}}{C_{0}-C_{1}},
$$

where $C_{0}$ is the oxygen concentration at the western boundary (147 $\left.\mu \mathrm{mol} / \mathrm{kg}\right), C_{1}$ is the observed mean oxygen concentration along $23^{\circ} \mathrm{W}$ between $2.5^{\circ} \mathrm{N}$ and $6.5^{\circ} \mathrm{N}(108 \mu \mathrm{mol} / \mathrm{kg})$, and $\overline{C_{23 W}}$ is the corresponding simulated value. This factor acts to damp changes of oxygen due to the background eddy diffusivity depending on the meridional and vertical oxygen curvature. That means if $\overline{C_{23 W}}$ is higher (lower) than $C_{1}$ the oxygen supply because of the background eddy diffusion decreases (increases).

The coefficients of the horizontal and the vertical eddy diffusion are chosen based on previous observational studies. We use a vertical diffusivity of $k_{z}=10^{-5} \mathrm{~m}^{2} / \mathrm{s}$ (Banyte et al., 2012; Fischer et al., 2013; Köllner et al., 2016). Hahn et al. (2014) suggested a meridional diffusivity $k_{y}$ of $500-1,400 \mathrm{~m}^{2} / \mathrm{s}$ between 100 and $300 \mathrm{~m}$ depth. Globally, previous studies suggest an anisotropy between zonal and meridional diffusivities with zonal diffusivity larger than meridional (Banyte et al., 2012; Eden, 2007; Eden \& Greatbatch, 2008; Kamenkovich et al., 2009). Brandt et al. (2010) found that $k_{y}=200 \mathrm{~m}^{2} / \mathrm{s}$ and $k_{x}=2.5 \times k_{y}\left(k_{x}\right.$ is the zonal diffusivity) best fits the observations in the ETNA OMZ ( $400 \mathrm{~m}$ depth). Here we calculate the equilibrium state for different $k_{y}$ and $k_{x}$. We found that a meridional eddy diffusivity of $k_{y}=800 \mathrm{~m}^{2} / \mathrm{s}$ with no anisotropy (i.e., $k_{x}=k_{y}$ ) and $u_{0}=0.055 \mathrm{~m} / \mathrm{s}$ results in oxygen concentrations along $23^{\circ} \mathrm{W}$ that best matches observations (Figures S1a and S1c in the supporting information). In the following, we will refer to this simulation as SIM 1.

\section{Results}

The interannual variability of the NEUC and its impact on the oceanic oxygen distribution are investigated using ship observations along $23^{\circ} \mathrm{W}$ and the output of TRATL01. First we briefly validate and discuss the zonal velocity and oxygen sections along $23^{\circ} \mathrm{W}$ TRATL01. Then we present the results of the interannual variability of the NEUC in TRATL01 before we focus on the oxygen response associated with NEUC variability. Finally, we present the results of the conceptual model to understand the role of specific mechanisms. 
Table 2

NEUC INT ( Sv), $Y_{C M}\left({ }^{\circ} \mathrm{N}\right)$ and Oxygen ( $\mu \mathrm{mol} / \mathrm{kg}$ ) Derived From Observations Along $23^{\circ} \mathrm{W}$ From 2002 to 2018

\begin{tabular}{lccccc}
\hline Date & $Y_{C M}$ & $I N T$ & (i) $\mathrm{O}_{2}$ & (ii) $\mathrm{O}_{2}$ & AMM \\
\hline 2002 Oct & 4.38 & 1.73 & & & $\circ$ \\
2003 Aug & 4.79 & 4.93 & & & $\circ$ \\
2006 Jun & 5.36 & 0.76 & 107.2 & 106.5 & $\circ$ \\
2006 Jun & 5.22 & 1.02 & 108.5 & 108.9 & $\circ$ \\
2006 Jun & 4.95 & 0.84 & 111.9 & 109.2 & $\circ$ \\
2008 Mar & 5.41 & 0.83 & 105.2 & 104.8 & $\circ$ \\
2008 Mar & 5.53 & 0.72 & & & $\circ$ \\
2009 Jul & 5.25 & 1.83 & & & - \\
2009 Nov & 4.47 & 2.42 & 106.1 & 103.7 & - \\
2009 Nov & 4.63 & 3.07 & & & - \\
2010 Feb & 4.60 & 2.84 & & & + \\
2010 May & 5.02 & 6.91 & & & + \\
2011 May & 4.96 & 0.08 & & & $\circ$ \\
2011 Aug & 5.24 & 5.83 & & & $\circ$ \\
2012 Nov & 5.12 & 2.02 & 98.1 & 96.6 & $\circ$ \\
2012 Nov & 4.83 & 1.51 & & & - \\
2014 May & 4.71 & 4.15 & 96.5 & 100.8 & - \\
2014 Nov & 4.76 & 3.45 & 104.7 & 104.5 & - \\
2015 Sep & 5.60 & 1.25 & 114.1 & 115.4 & - \\
2016 Aug & 4.49 & 2.10 & 110.0 & 108.1 & $\circ$ \\
2018 Feb & 4.74 & 5.80 & 108.5 & 107.2 & - \\
total mean single sections & $4.96 \pm 0.08$ & $2.58 \pm 0.42$ & $107.1 \pm 1.8$ & $106.0 \pm 1.5$ & \\
mean section (2002-2018) & 4.84 & 1.36 & 107.7 & 106.1 & \\
\hline
\end{tabular}

Note . NEUC = North Equatorial Undercurrent; $\mathrm{AMM}=$ Atlantic meridional mode. The oxygen values are derived in two ways. (i) The values are average in a meridionally varying frame (100- to 300-m depth, $\left(Y_{C M}-\right.$ $\left.1.5)^{\circ}-\left(Y_{C M}+1\right)^{\circ} \mathrm{N}\right)$. (ii) The values are averaged in a fixed box (100 to $300 \mathrm{~m}$ depth, $\left.3^{\circ}-6.5^{\circ} \mathrm{N}\right)$. The state of the AMM is marked for positive events (+), negative events (-), and neutral phases (o). For the mean values derived from the single ship sections, the standard error is given.

\subsection{Mean Velocity and Oxygen Section Along $23^{\circ} \mathrm{W}$}

In the mean ship section along $23^{\circ} \mathrm{W}$, below the mixed layer, higher oxygen concentrations locally coincide with the eastward-flowing EUC, NEUC, and nNECC at $0^{\circ} \mathrm{N}, 4.5^{\circ} \mathrm{N}$, and $8.5^{\circ} \mathrm{N}$, respectively, whereas the westward flows centered at $2.5^{\circ} \mathrm{N}$ and $6.5^{\circ} \mathrm{N}$ are associated with lower oxygen concentrations (Figures 2a and 2c). The core of the ETNA OMZ with oxygen concentrations of $40 \mu \mathrm{mol} / \mathrm{kg}$ is located between 400 and $500 \mathrm{~m}$ and between $9^{\circ} \mathrm{N}$ and $13^{\circ} \mathrm{N}$. In the upper $250 \mathrm{~m}$ south of $6^{\circ} \mathrm{N}$, oxygen concentration are in general higher than north of $6^{\circ} \mathrm{N}$. This is associated with the more energetic zonal flow in the near-equatorial belt including the NEUC.

From the observed zonal velocity field the NEUC intensity (INT, equation (2)) and central position $\left(Y_{C M}\right.$, equation (1)) are calculated and averaged in two different ways: (i) They are calculated using the mean ship section. Here the averaged NEUC intensity is $1.2 \mathrm{~Sv}$, and the current is on average located at $4.9^{\circ} \mathrm{N}$. (ii) The estimates of the single ship sections are averaged. This results in an average intensity of $2.6 \pm 0.4 \mathrm{~Sv}$ and an averaged central position of $5.0 \pm 0.1^{\circ} \mathrm{N}$ (Table 2). Method (ii), which results in higher values, is more consistent with the method used for the model output.

Similar to the observations, oxygen concentrations along $23^{\circ} \mathrm{W}$ in TRATL01 are increased in the presence of eastward flow and decreased in the presence of westward flow (Figures $2 \mathrm{~b}$ and 2d). The NEUC in TRALT01 is on average more than twice as strong as in the observations, and its core is located a bit further south. The mean NEUC intensity at $23^{\circ} \mathrm{N}(1990-2007)$ is $7.4 \pm 0.3 \mathrm{~Sv}$, and its mean central position is $4.44 \pm 0.03^{\circ} \mathrm{N}$. The model is overestimating the strength and depth range of the NEUC and the nSEC whereas weaker eastward current bands such as the NICC and the nNECC are not well represented by the model. 
In TRATL01 oxygen concentrations below the mixed layer are generally lower, the OMZ is located shallower, and the difference between local oxygen maxima and minima is smaller compared to observations. The core of the OMZ in TRATL01 is $200 \mathrm{~m}$ shallower than in observations. Also, the deep oxygen maximum at the equator is not well represented in TRATL01. Although the NEUC is stronger, oxygen concentrations within the NEUC region at $23^{\circ} \mathrm{W}\left(100\right.$ to $300 \mathrm{~m}$ depth, $\left.3^{\circ}-6.5^{\circ} \mathrm{N}\right)$ are lower in TRATL01 $(93.4 \pm 0.8 \mu \mathrm{mol} / \mathrm{kg})$ compared to observations $(106.0 \pm 1.5 \mu \mathrm{mol} / \mathrm{kg})$.

Different mechanisms seem to dominate the NEUC mean state in observations and in TRATL01. Not only the NEUC is very strong in TRALT01 but also the nSEC south of it. One explanation for that can be a too strong recirculation between nSEC and NEUC. In the ship section from February 2018, a temporary recirculation between the nSEC and NEUC seems to exist (black dashed rectangles in Figures 1b and 1c). Here the velocity maximum between $3^{\circ} \mathrm{N}$ and $5^{\circ} \mathrm{N}$ in the depth range of 50 to $300 \mathrm{~m}$ is associated with rather low oxygen, and it is located above and south of the NEUC associated oxygen maximum. It is likely that this eastward velocity maximum is a temporary recirculation of the nSEC, which overlaps with the actual NEUC flow. This results in lower oxygen values associated with higher eastward NEUC velocities. An overestimation of this process by TRATL01 could result in the shown discrepancies between model and observations. Strong recirculation between EUC, NEUC, and nSEC are also shown in other model studies such as Hüttl-Kabus and Böning (2008).

In summary, distinct discrepancies exist between simulated and observed zonal velocities and oxygen concentration in the mean sections along $23^{\circ} \mathrm{W}$. A potential cause for the differences in the mean state is an overestimation of the recirculation between nSEC and NEUC in TRATL01. Nevertheless, we want to emphasize here that the horizontal oxygen distribution is clearly improved in TRATL01 compared to coarser resolution models (Duteil et al., 2014). How the erroneous representation of the mean state in TRATL01 affects the NEUC and associated oxygen changes on interannual time scales will be investigated in section 3.4. Before we focus on the oxygen response to the NEUC we investigate the variability of NEUC transports and central position. In the next section we briefly study the seasonal cycle of the NEUC in observations and in TRATL01.

\subsection{Seasonal Cycle of NEUC Intensity (INT) and Central Position $\left(Y_{C M}\right)$}

In the previous section we found that on average the NEUC is too strong in TRATL01 but simultaneously shows a weaker oxygen maximum along $23^{\circ} \mathrm{W}$ compared to observations. We hypothesize that this might be due to an overestimation of the recirculations between NSEC and NEUC in TRALT01. Here we focus on the seasonal cycle of the NEUC in observations and in TRATL01.

The NEUC transport estimates derived from the observational data are highly variable and show no clear seasonal signal (Table 2 and black dots in Figure 3a). This is in agreement with previous observational results (Bourlès et al., 2002, 1999; Brandt et al., 2006; Schott et al., 1995, 2003; Urbano et al., 2008). The current is weak and likely to be obscured by mesoscale activities (e.g., Goes et al., 2013; Weisberg \& Weingartner, 1988) and interannual variability (Goes et al., 2013; Hüttl-Kabus \& Böning, 2008). Even with this unique data set of 21 ship sections, observations are still too sparse to identify a seasonal variability of the NEUC.

In TRATL01, the NEUC shows a clear seasonal cycle. Along $23^{\circ} \mathrm{W}$, the NEUC reaches its maximum intensity of 11.4 Sv in May and its minimum intensity of 3.9 Sv in November (red line in Figure 3a). Its central position shows a semiannual cycle with southernmost positions in September and January and northernmost positions in May and November (Figure 3b). The semiannual cycle of NEUC central position is not visible at all longitudes (Figure 3d). The seasonal signal of NEUC INT and $Y_{C M}$ is propagating from the eastern boundary toward the west (Figures $3 \mathrm{c}$ and $3 \mathrm{~d}$ ). Highest standard deviations of NEUC transports occur during May and June in the eastern basin and during July and August in the western basin (black contours in Figure 3c). Maximum standard deviation of NEUC transports seems to be associated with the seasonal weakening of the NEUC.

The seasonal cycle of the NEUC in TRATL01 generelly agrees with previous studies. Hüttl-Kabus and Böning (2008) also found a more northward position and higher transports between April and August and a more southward position and lower transports between September and March in their model simulation. The seasonal cycle of NEUC transport estimates in TRATL01 is also consistent with the synthesis product of Goes et al. (2013). Similar to Goes et al. (2013), we found a semiannual cycle of the NEUC central position 
a)
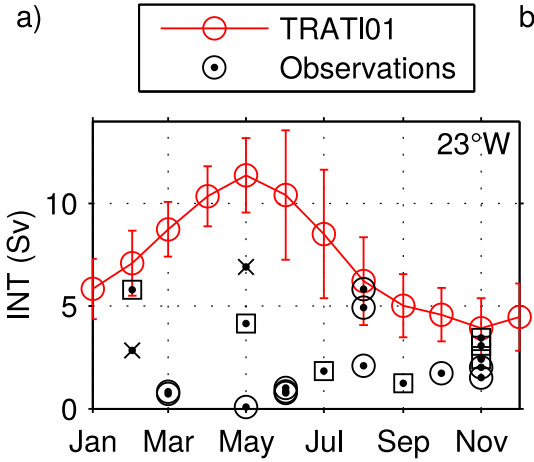

c)

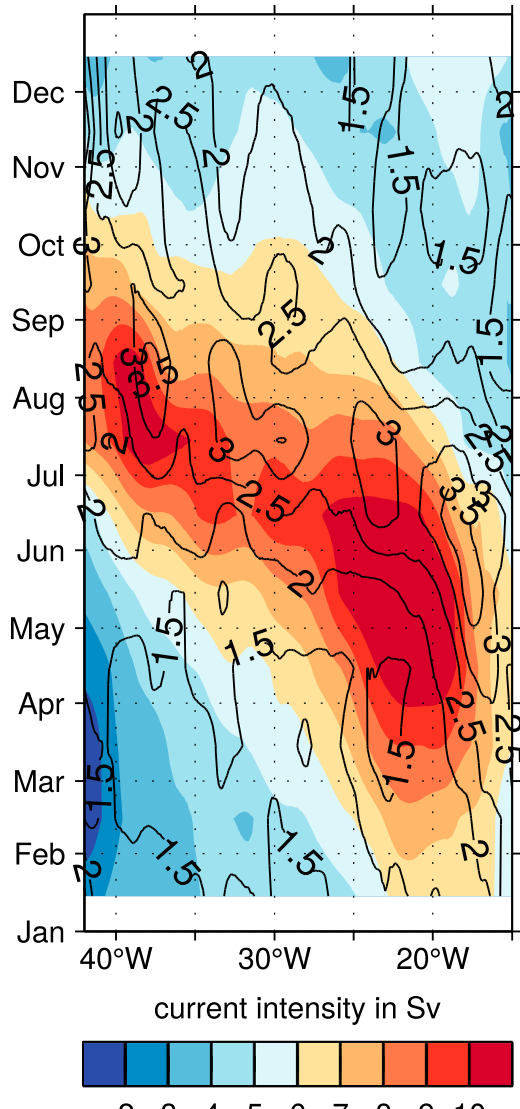

b)

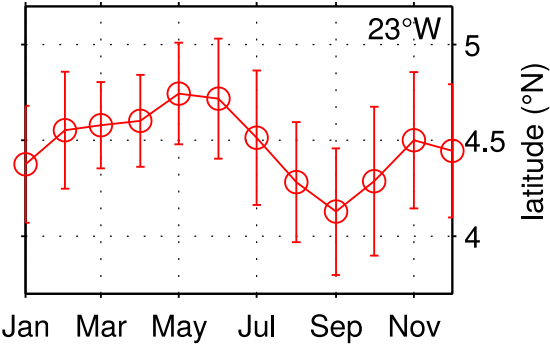

d)

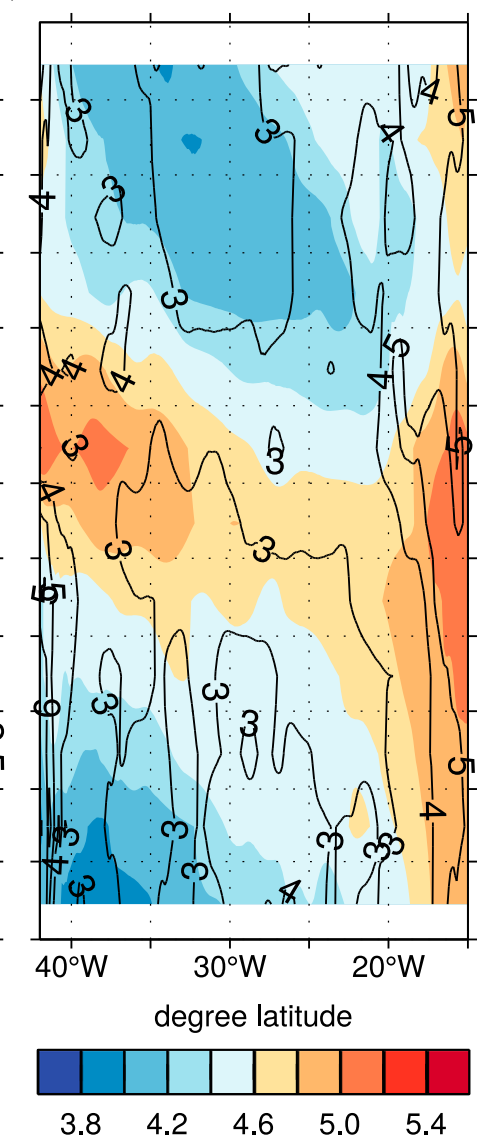

Figure 3. Seasonal cycle of (a) North Equatorial Undercurrent (NEUC) intensity (INT) and (b) NEUC central position $\left(Y_{C M}\right)$ at $23^{\circ} \mathrm{W}$ derived from TRATL01 (red lines, 1958-2007) as well as NEUC INT derived from each ship section (black dots in a; circles, squares, and crosses mark years of neutral, negative, and positive Atlantic Meridional Mode phases, respectively). The red bars denote the standard deviations of NEUC INT and $Y_{C M}$ in TRALT01 of the respective months from 1958 to 2007. Hovmöller diagram of the 1958-2007 seasonal cycle of (c) INT and (d) $Y_{C M}$ in TRATL01 for each longitude. The black contours show the standard deviation of (c) INT in Sv and (d) $Y_{C M}$ in degree latitude for each month from 1958 to 2007.

along $23^{\circ} \mathrm{W}$, although the timing of maxima and minima is shifted by up to 2 months. We found minima in September and January and maxima in May and November, whereas in Goes et al. (2013) minima occur in September and March and maxima in August and December. In general, the seasonal strengthening of the eastern NEUC in TRATL01 seems to coincide with the northward migration of the Intertropical Convergence Zone (ITCZ) and the shoaling of the thermocline in the eastern equatorial Atlantic (Xie \& Carton, 2004). 
a)

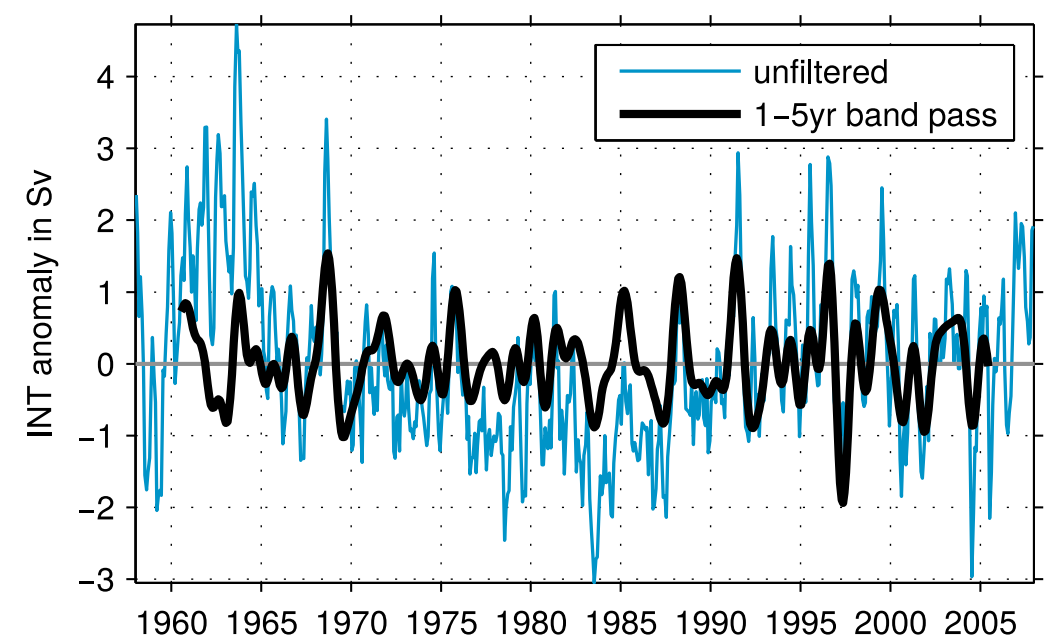

b)

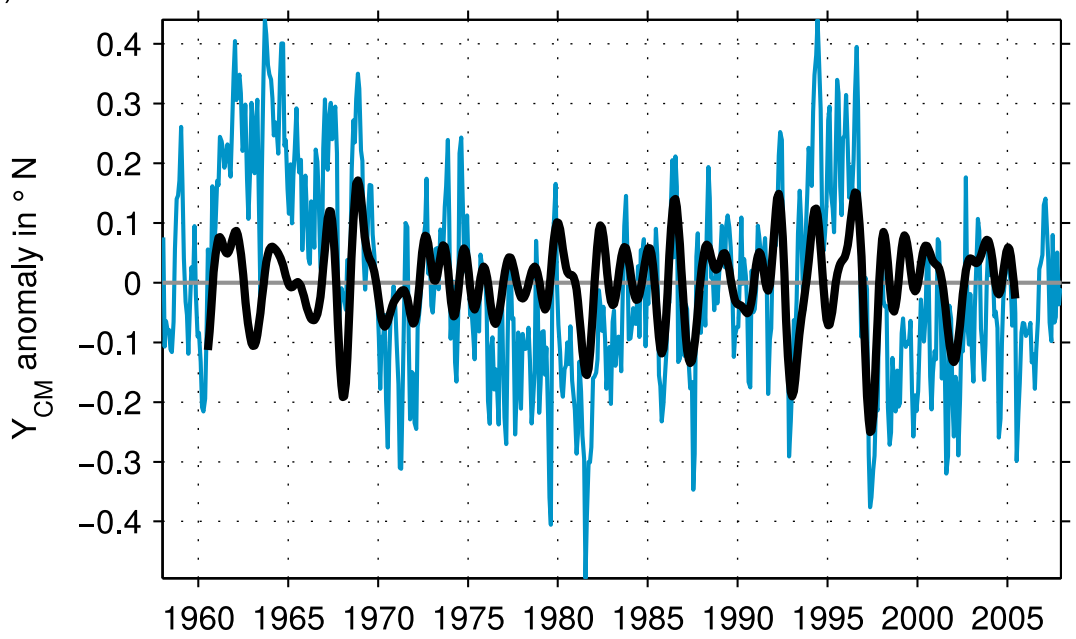

Figure 4. Zonally averaged $\left(42^{\circ}-15^{\circ} \mathrm{W}\right)$ monthly mean anomaly of (a) North Equatorial Undercurrent $I N T$ (equation (2)) and (b) $Y_{C M}$ (equation (1)) with respect to the 1958-2007 seasonal cycle estimated from TRATL01. A 1to 5-year band-pass (black line) Butterworth filter is applied to the zonally averaged time series (blue lines).

In summary, a seasonal and longer-term variability of the NEUC in observations cannot be identified. In TRATL01 the NEUC shows a clear seasonal cycle that is in general agreement with previous studies. This encourages us to study the interannual variability of the NEUC in the next section.

\subsection{Interannual Variability of the NEUC}

The NEUC transport and central position vary on interannual to multidecadal time scale in TRATL01 (Figure 4). However, TRATL01 is driven by CORE v2 wind forcing that is based on NCEP winds. The CORE forcing as well as the NCEP wind is known to exhibit spurious multidecadal wind variability (Fiorino, 2000; He et al., 2016; Hurrell \& Trenberth, 1998). We therefore focus on the interannual variability of the NEUC in TRATL01.

NEUC transport and central position show a positive correlation in TRATL01. To analyze the correlation, we zonally averaged NEUC $I N T$ and $Y_{C M}$ from $42^{\circ} \mathrm{W}$ to $15^{\circ} \mathrm{W}$ and removed the seasonal cycle from 1958 to 2007 (blue lines in Figure 4). To better understand the role of interannual variability of the NEUC, we applied a 1to 5-year band-pass Butterworth filter to INT and $Y_{C M}$ (black lines in Figure 4). Higher NEUC transports are generally associated with a more northward position of the NEUC and vice versa with a significant positive correlation between the band-pass filtered time series of $R=0.33$. 
a)

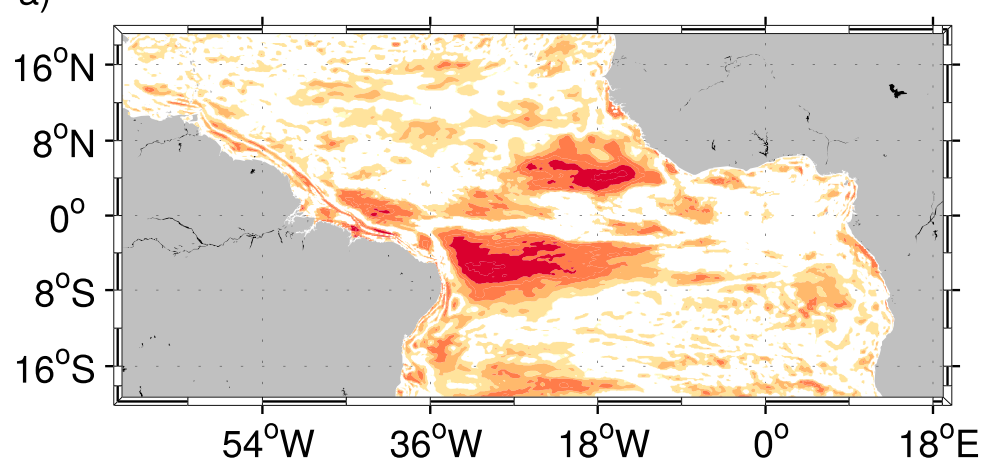

$\mathrm{R}$

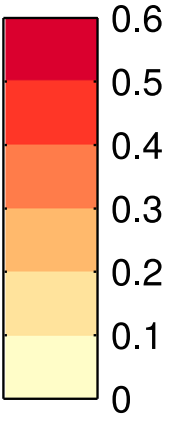

b)

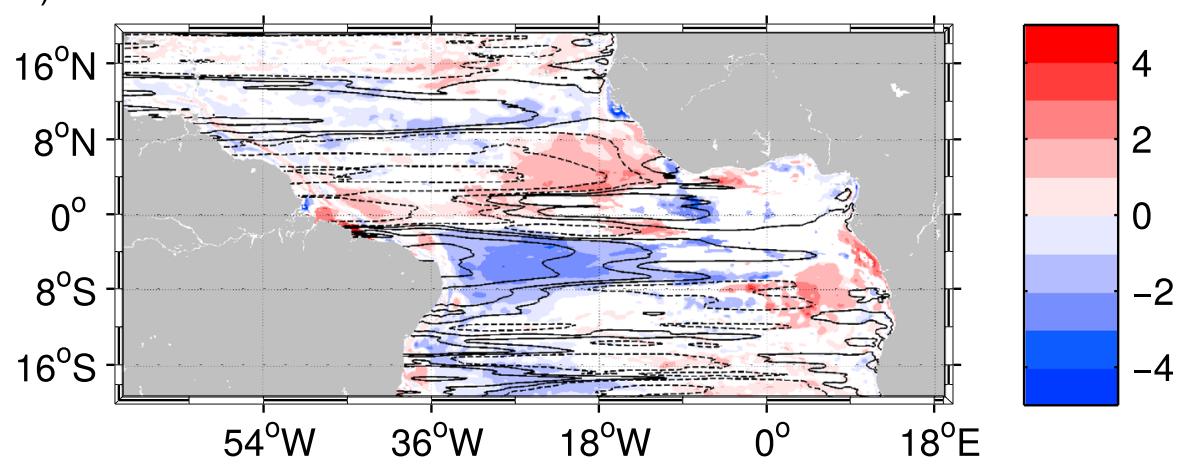

Figure 5. Linear regression of 1- to 5-year band-pass filtered North Equatorial Undercurrent INT onto wind stress curl from TRATL01. (a) Coefficient of correlation and (b) slope of the linear regression. Contours in (b) present the anomalous Sverdrup circulation forced by a wind stress curl anomaly that causes a North Equatorial Undercurrent transport anomaly of $1 \mathrm{~Sv}$. The black solid lines mark the $0,0.1,0.4$, and $1 \mathrm{~Sv}$ isoline and the black dashed lines mark the $-0.1,-0.4$, and -1 Sv isoline.

Previous studies suggest the upwelling in the Guinea Dome and along the Northwest African coast in the ETNA as a possible driver of the NEUC (Furue et al., 2007, 2009) and that changes in the wind field can impact the upwelling, which in turn leads to changes in the NEUC (Goes et al., 2013). To investigate this connection, we perform a linear regression of the band-pass filtered NEUC INT onto the wind stress curl using monthly time series regressed at lag 0 (Figure 5). On interannual time scales, the wind stress curl explains up to $40 \%$ of the NEUC variability. Maximum positive correlation $(R=0.6)$ is found in the eastern basin of the tropical North Atlantic between $2^{\circ} \mathrm{N}$ and $8^{\circ} \mathrm{N}$ and in the western basin of the tropical South Atlantic between $0^{\circ}$ and $8^{\circ} \mathrm{S}$. This large-scale wind pattern may not only impact the strength of the NEUC but also effect the basin-wide circulation. We therefore regressed the wind stress curl on the NEUC and calculate the anomalous Sverdrup streamfunction from the derived slope $b$ times a unit transport of $1 \mathrm{~Sv}$.

During a strong (weak) NEUC, the derived anomalous Sverdrup streamfunction is associated with a westward (eastward) velocity anomaly between $8^{\circ} \mathrm{N}$ and $10^{\circ} \mathrm{N}$ and an eastward (westward) velocity anomaly just south off the equator (Figure 5). At the western boundary the closure of the anomalous Sverdrup streamfunction would result in a southward (northward) and northward (southward) velocity anomaly north and south of the equator, respectively. Between $40^{\circ} \mathrm{W}$ and $10^{\circ} \mathrm{W}$ just north of the equator the wind stress curl anomaly leads to an anomalous northward (southward) Sverdrup transport. To further investigate the relationship between the NEUC and the large-scale wind field, we perform a composite analysis regarding the wind and SST field during strong and weak NEUC transports.

The band-pass filtered time series of NEUC INT is used to define years of strong and weak NEUC flow. As threshold 0.6 times its standard deviation is chosen (green line in Figure 6a). Then composites of SST and the wind field are calculated for years of strong and weak NEUC transports (Figures $6 \mathrm{~b}$ and $6 \mathrm{c}$ ). The composites show an interhemispheric SST gradient with opposite sign for strong and weak NEUC transports. Associated 


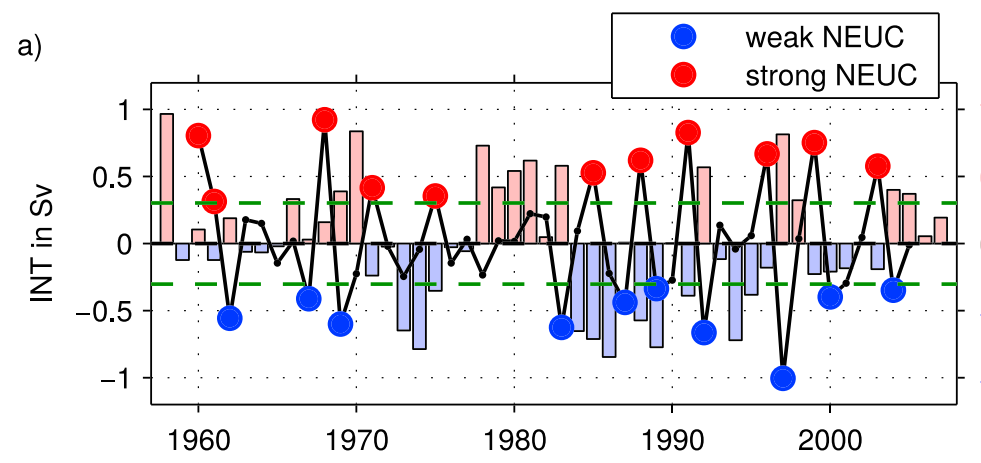

b) strong NEUC - MAM
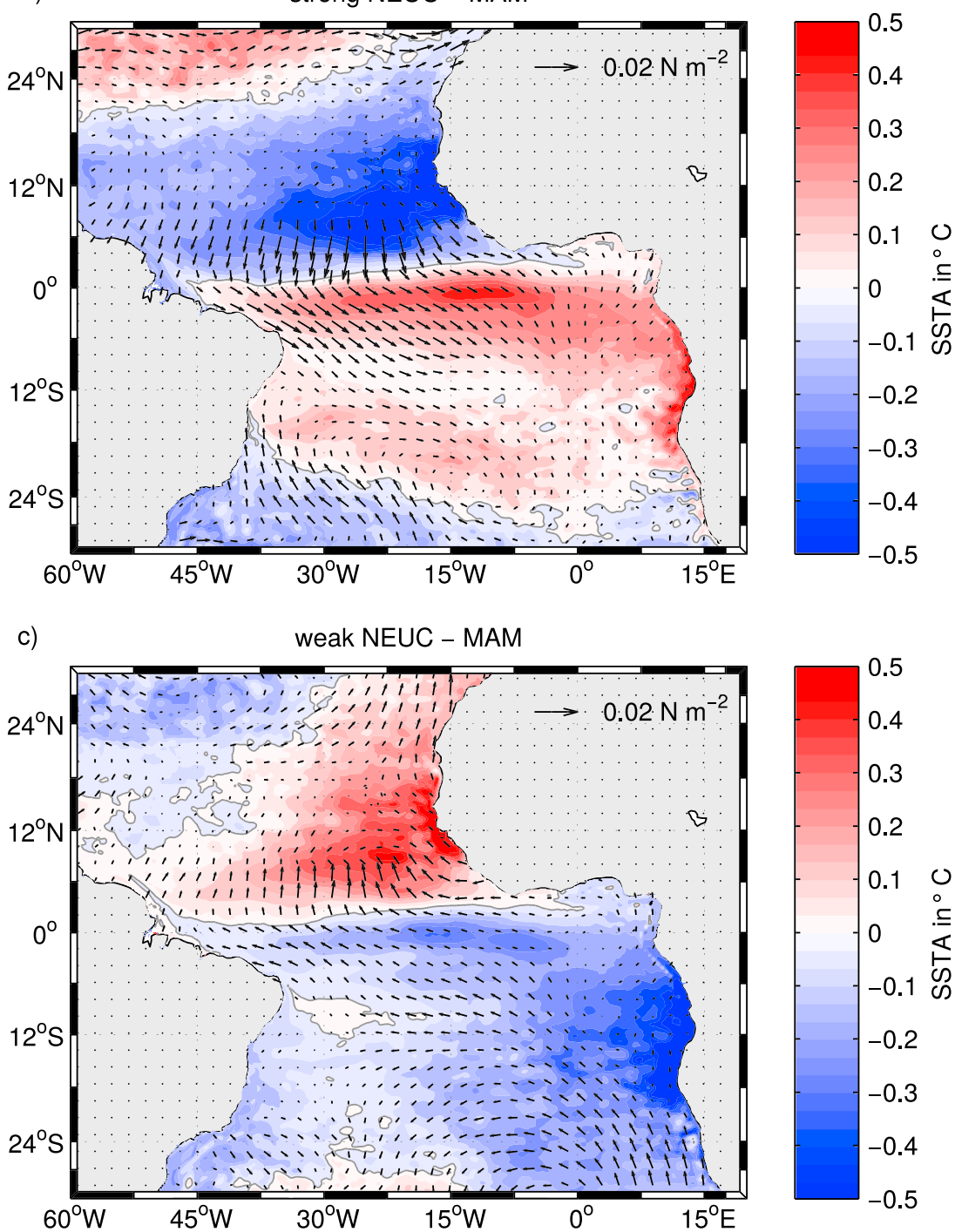

Figure 6. (a) Annual mean of North Equatorial Undercurrent (NEUC) $I N T$ anomaly averaged between $42^{\circ} \mathrm{W}$ and $14^{\circ} \mathrm{W}$. A 1- to 5-year band-pass filter is applied to the time series (left $y$-axis). The green dashed line marked \pm 0.6 times the standard deviation of the time series. Red dots mark years of strong NEUC INT; blue dots mark years of weak NEUC INT. The bars show the March to May (MAM) averages of the Atlantic meridional mode (AMM) index after Servain (1991) (right $y$-axis). Composites of anomalous sea surface temperature (SST; color shading) and surface wind stress (arrows) for years of (b) strong and (c) weak NEUC INT. 
are wind anomalies pointing from the colder hemisphere toward the warmer hemisphere. These are the characteristics of the AMM as described in the introduction. The interannual NEUC variability is negatively correlated with the AMM. A positive AMM is associated with a weaker and more southern NEUC, and the negative AMM is associated with a stronger and more northern NEUC.

The anomalous interhemispheric winds during an AMM event link the interannual variability of the NEUC to the AMM. Associated with a positive (negative) AMM event is a negative (positive) wind stress curl anomaly along the equator and just north of it east of $20^{\circ} \mathrm{W}$ (Foltz \& McPhaden, 2010b; Joyce et al., 2009). We find a similar wind pattern for weak and strong NEUC, respectively (Figure 5). The large-scale wind pattern does not only affect the NEUC flow but also affects the basin-wide Sverdrup circulation in the tropical Atlantic (Figure 5). The anomalous northward Sverdrup transport between $40^{\circ} \mathrm{W}$ and $10^{\circ} \mathrm{W}$ just north of the equator might impact the recirculation between the NEUC and the nSEC. Furthermore, along the Northwest African coast south of $15^{\circ} \mathrm{N}$, we find alongshore wind stress that act to weaken (strengthen) coastal upwelling during weak (strong) NEUC transports (Figure 6).

In summary, in TRATL01 the interannual variability of the NEUC is linked to the AMM, likely due to its associated large-scale wind anomalies. Consistent with the results of Goes et al. (2013), we find a strengthening and a more northward position of the NEUC during negative AMM events and vice versa. The anomalous wind stress curl additionally impacts the Sverdrup circulation between $10^{\circ} \mathrm{S}$ and $10^{\circ} \mathrm{N}$. The response of oxygen to the interannual changes of the NEUC in TRATL01 is investigated in the next section.

\subsection{NEUC Impact on Oxygen}

On interannual time scales the NEUC variability is linked to the AMM in TRATL01. During positive AMM events, the NEUC transports are weaker, and the current core is displaced toward the south. During negative AMM events, the NEUC is stronger and displaced toward the north. In this section we investigate the impact of the interannual NEUC variability on oxygen. Brandt et al. (2010) suggest that weaker NEUC transports lead to lower oxygen concentrations at $23^{\circ} \mathrm{W}$ due to a weaker advection of oxygen-rich water masses from the western boundary. Consequently, we expect lower oxygen concentrations after positive AMM events and vice versa. The observational data show no clear connection between oxygen concentration, NEUC transports, and the AMM (Figure S2). We will therefore focus on the interannual variability of oxygen in TRATL01.

In TRATL01 the oxygen variability is analyzed along three characteristic neutral density $\left(\gamma_{n}\right)$ surfaces of the NEUC. We choose the $25.5 \mathrm{~kg} / \mathrm{m}^{3}$ surface for the upper part of the NEUC, the $26.5 \mathrm{~kg} / \mathrm{m}^{3}$ surface for the central part of the NEUC, and the $26.9 \mathrm{~kg} / \mathrm{m}^{3}$ surface for the lower part of the NEUC (Figure 2). The mean oxygen concentrations and horizontal velocities along all three $\gamma_{n}$ surfaces of the period 1990 to 2007 are shown in Figure 7. Along the upper $\gamma_{n}$ surface in the area of the nSEC and NEUC low oxygen concentrations exist (Figure 7a). Interestingly, minimum oxygen concentrations are found in the western basin in the area of the nSEC supplying the eastward flow within the NEUC. This suggests that the water masses in the upper NEUC in TRATL01 are only weakly connected to the oxygen-rich waters in the western boundary and are instead provided largely out of the recirculation between NEUC and nSEC. A possible mechanism causing the low-oxygen values along the $25.5 \mathrm{~kg} / \mathrm{m}^{3}$ surface close to the western boundary might be a too weak or inexistent intermediate current system in TRATL01. This would lead to a too low ventilation at depth, which again can result in an upward flux of low-oxygen waters toward the surface due to either diapycnal mixing or vertical advection within the subthermocline cells (Perez et al., 2014; Wang, 2005).

Along the $26.5 \mathrm{~kg} / \mathrm{m}^{3}$ surface oxygen concentrations are high in the western basin and low in the eastern basin (Figure 7b). At the northern flank of the NEUC and north of it a tongue of high oxygen concentrations spreads toward the east. At the southern flank of the NEUC and within the nSEC a tongue of low oxygen spreads toward the west. The mean horizontal current field in combination with the oxygen concentrations indicates that the NEUC in TRATL01 is partly supplied by water masses from the western boundary and partly by water masses from the nSEC. This supports our previous hypothesis that in TRATL01 a constant recirculation between nSEC and NEUC superimposed on a mean eastward current results in a strong NEUC flow that is associated with low oxygen levels, as it is supplied by the oxygen-poor water masses out of the nSEC.

At the lower part of the NEUC (26.9- $\mathrm{kg} / \mathrm{m}^{3}$ surface) a tongue of high oxygen concentration centered at the NEUC spreads from the western to the eastern basin (Figure 7c). Here the ventilation of the NEUC by the 

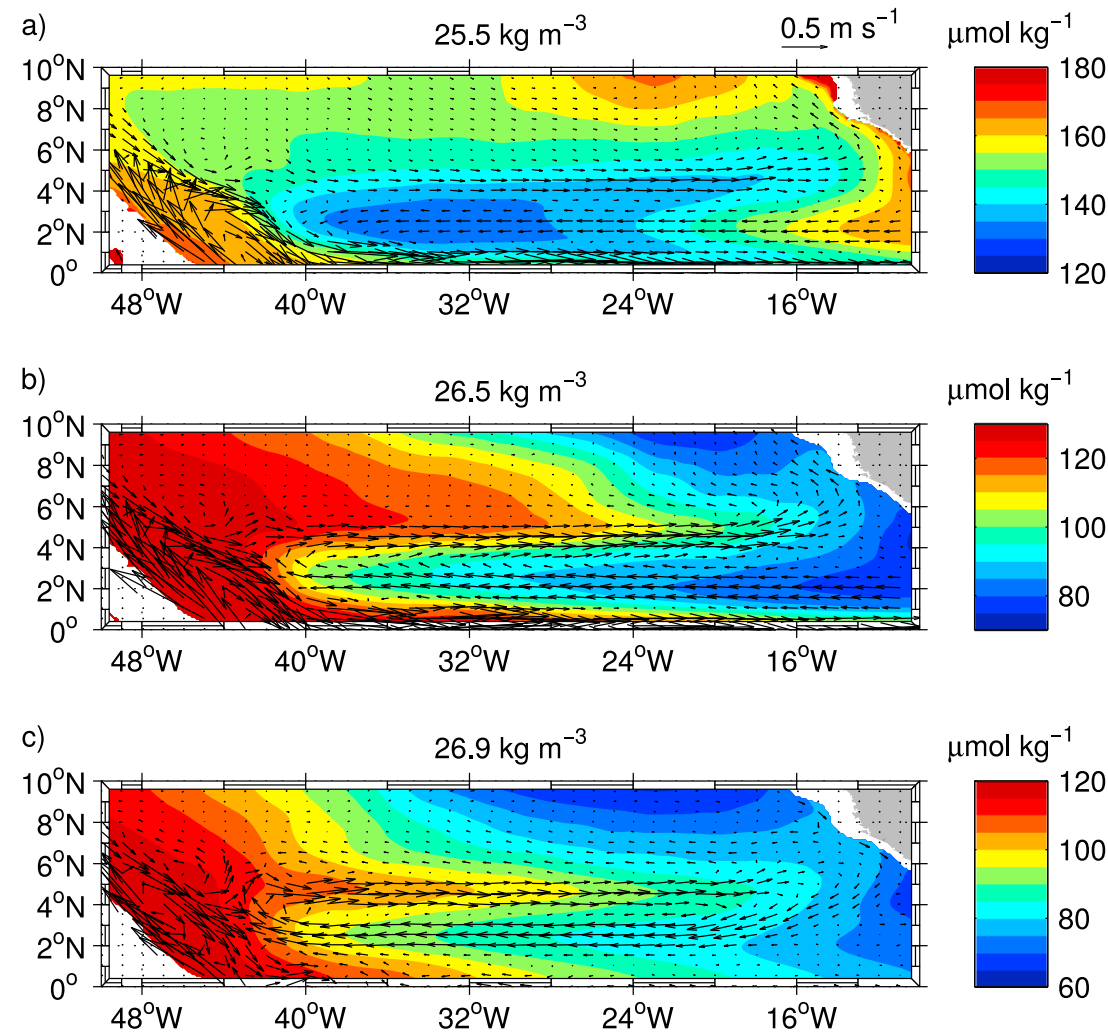

Figure 7. Mean oxygen concentration (shading) and horizontal velocities (arrows) for the period 1990 to 2007 along three characteristic isopycnals $\left(25.5,26.5\right.$, and $\left.26.9 \mathrm{~kg} / \mathrm{m}^{3}\right)$ of the North Equatorial Undercurrent in TRALT01.

western boundary seems to dominate the water supply of the NEUC with only weak recirculation occurring along the eastward path of the NEUC. Note that eastward flow of waters with higher oxygen concentrations associated with the NEUC reaches the eastern boundary north of $6^{\circ} \mathrm{N}$.

To investigate interannual variability of oxygen in TRATL01, the seasonal cycle is removed from the oxygen field, and a 5-year high-pass Butterworth filter is applied to the annual averaged oxygen anomalies. Similar to the SST and wind stress analysis, composites of oxygen and horizontal velocity for strong and weak NEUC transports are calculated (Figure 8). We now focus on the oxygen variability along the $26.5 \mathrm{~kg} / \mathrm{m}^{3}$ surface representing the core depth of the NEUC in TRATL01.

At a first glance, the oxygen anomalies associated with the NEUC variability in TRATL01 appear to be counterintuitive. Along the 26.5-isopycnal during years of weak NEUC, positive oxygen anomalies exist along the NEUC path with a connection to the southwestern boundary (Figure 8a). For years of strong NEUC flow, negative oxygen anomalies occur along the NEUC path instead (Figure 8b). This is the opposite of what we would have expected taken into account the mean velocity and oxygen fields along $23^{\circ} \mathrm{W}$.

Again, a too strong recirculation between the nSEC and NEUC might explain the oxygen pattern in TRALT01. The composite analysis shows that during weak (strong) NEUC flow, also, the nSEC is weak (strong) and is transporting less (more) oxygen-poor water to the western basin (Figure 8). Associated is a weaker (stronger) than normal recirculation between NEUC and nSEC, and the NEUC is supplied by less (more) oxygen-poor water from the nSEC. Additionally a weak (strong) nSEC is transporting less (more) oxygen-poor water to the western basin. Positive (negative) oxygen anomalies develop in the western basin, which may be then advected by the NEUC toward the east.

In the oxygen composites, anomalies occur in the entire tropical North Atlantic, which might be associated with the detected large-scale wind anomalies during anomalous NEUC transports. For example, weak negative (positive) oxygen anomalies exist along the western boundary during strong (weak) NEUC phases and cover a depth range of 50 to $450 \mathrm{~m}$ depth. These oxygen anomalies are associated with weak meridional velocity anomalies that act to weaken (strengthen) the NBC and its return flow. This pattern could be 


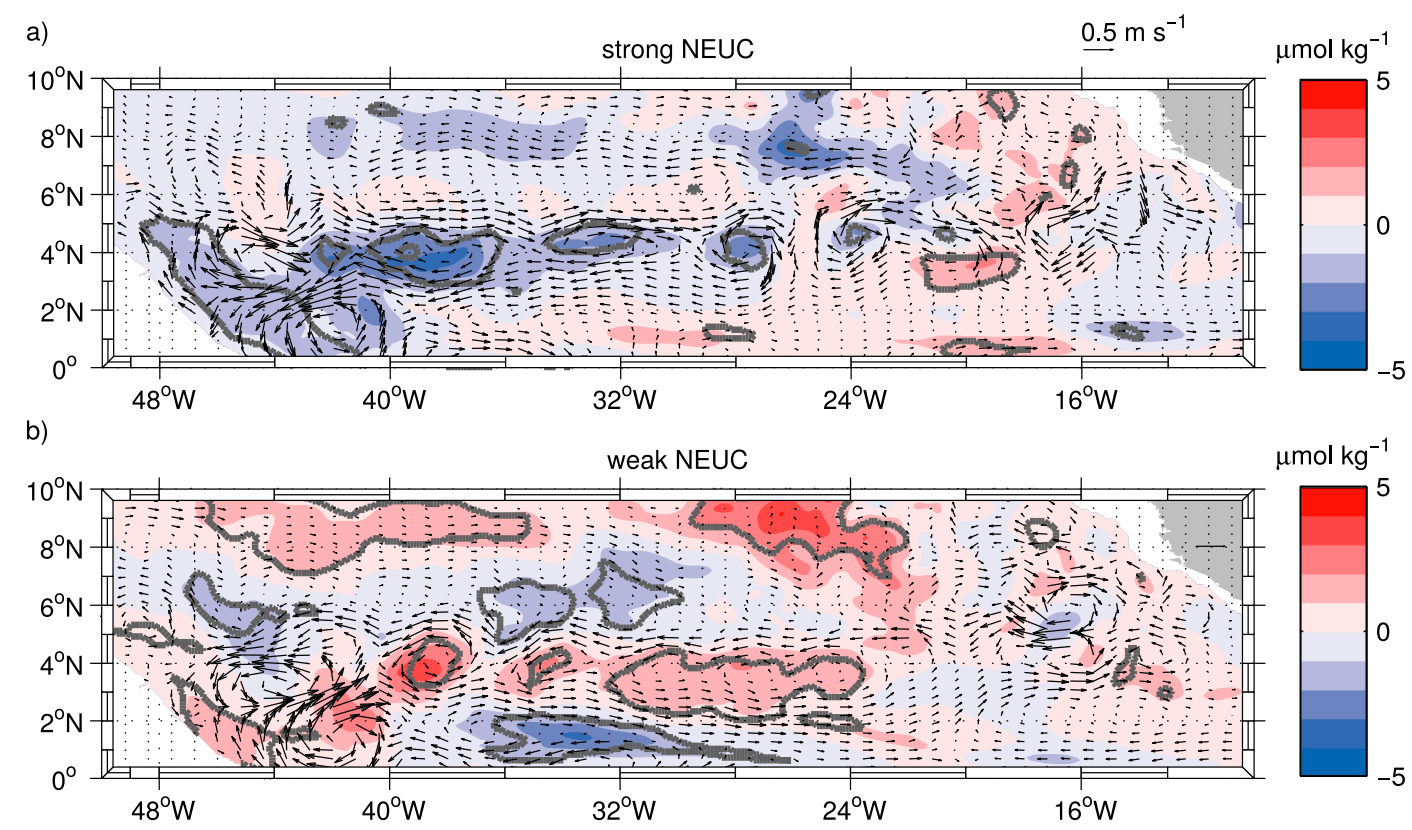

Figure 8. Anomalous oxygen concentrations (shading) and horizontal velocities (arrows) for years of strong (a) and weak (b) North Equatorial Undercurrent (NEUC) flow along the $26.5 \mathrm{~kg} / \mathrm{m}^{3}$-isopycnal in TRATL01. The annual mean data were 5-year high-pass filtered. Areas within the gray contour lines mark oxygen anomalies that are significant at a 95\% confidence level.

related to the closure of the Sverdrup circulation at the western boundary (Figure 5b). The wind field during strong (weak) NEUC and negative (positive) AMM events acts to weaken (strengthen) the NBC just north of the equator so that less (more) oxygen-rich water might be supplied there. Furthermore, negative (positive) oxygen anomalies during strong (weak) NEUC flow exist also north of $7^{\circ} \mathrm{N}$. Here we find westward (eastward) velocity anomalies in the anomalous Sverdrup streamfunction at about $8^{\circ} \mathrm{N}$ that are also visible in Figure 8. This westward (eastward) velocity anomaly act to weaken (strengthen) the nNECC, which again could explain the oxygen anomalies there.

In contrast to our expectations, the NEUC strength and the oxygen concentrations along its flow path are negatively correlated on interannual time scales in TRATL01. To get a rough estimate of how much of the oxygen variability can be explained by the NEUC variability, we perform a lagged linear regression of oxygen on NEUC INT for the 1- to 5-year band-pass filtered time series (Figure 9). The linear regression supports the results from the composite analysis, that is, a negative correlation between oxygen and NEUC in TRATL01 (Figure 9). Highest values of R occur along and slightly south of the NEUC pathway mainly between $42^{\circ} \mathrm{W}$ and $24^{\circ} \mathrm{W}$ (Figures 9a-9d). Here on average the NEUC variability can explain between $20 \%$ and $40 \%$ of the oxygen variability. Maximum $R$ values occur just south of the NEUC west of $36^{\circ} \mathrm{W}$ when the NEUC leads the oxygen by 3 months. This hints again toward the relationship between nSEC and NEUC. If the nSEC is weak, less oxygen-poor water is transported toward the west, leading to a positive oxygen anomaly there that is maximum 3 months after nSEC is weakest. Striking is also the high correlation near the equator in Figure 9e, suggesting that the oxygen variability there leads the NEUC variability further north. A possible explanation might be that the variability of the near-equatorial flow is leading the variability of the NEUC. A lead-lag correlation between NEUC INT and the zonal velocity shows eastward velocity anomalies along the equator leading an anomalous strong NEUC by 3 months, but the correlation is low.

We here want to briefly discuss the role of respiration for oxygen variability. Generally, respiration can be another mechanism changing the oxygen concentration. However, on interannual time scales the variability of respiration in TRATL01 is too small to have a significant effect on oxygen. This is consistent with other studies showing that circulation changes are the dominant mechanism setting the variability of oxygen levels on seasonal and multidecadal time scales (Montes et al., 2014; Pozo Buil \& Di Lorenzo, 2017; Vergara et al., 2016; Yang et al., 2017). 
a)

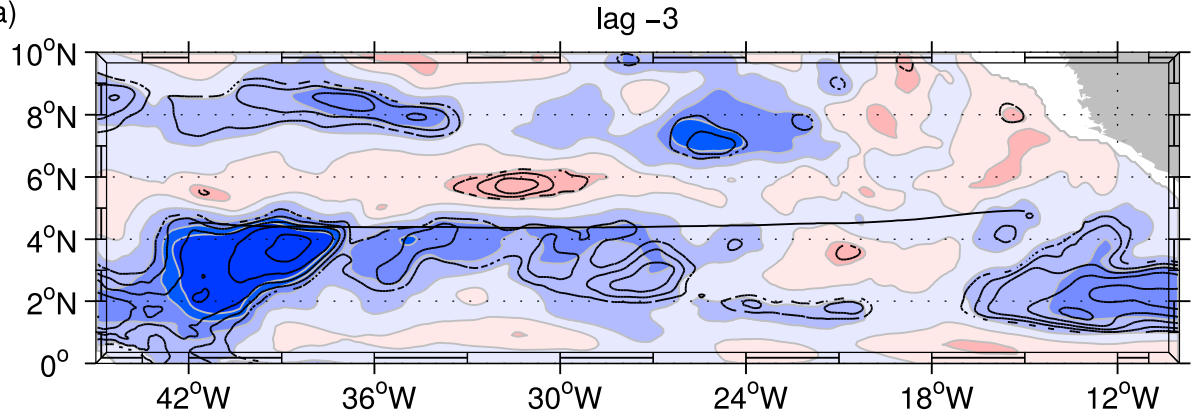

b)

$\operatorname{lag} 0$

$\mu \mathrm{mol} \mathrm{kg}{ }^{-1} \mathrm{~Sv}^{-1}$

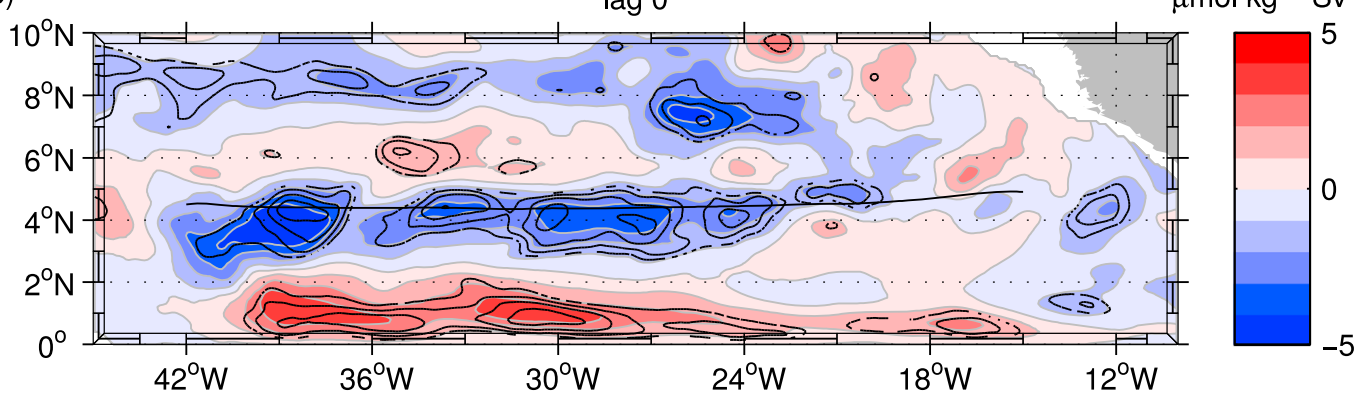

c)

$\operatorname{lag} 3$

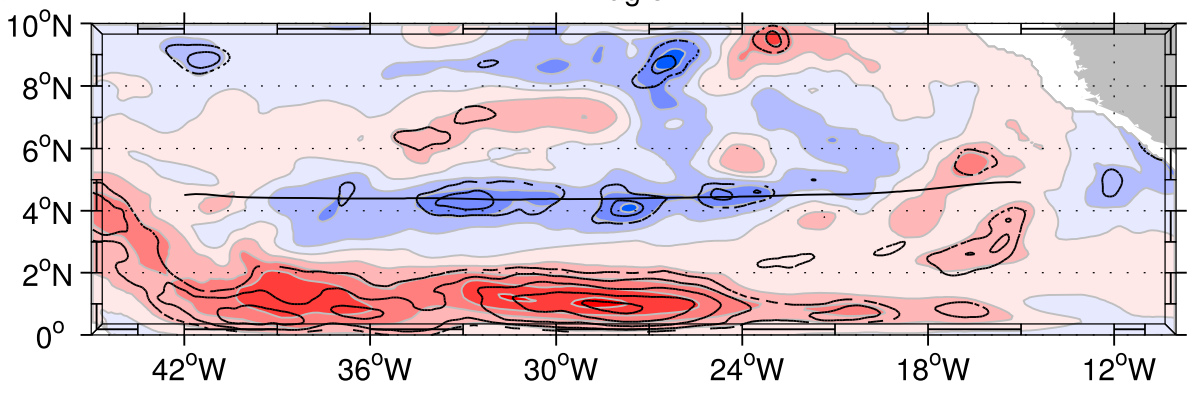

Figure 9. Linear regression of TRATL01 oxygen concentrations along the $26.5 \mathrm{~kg} / \mathrm{m}^{3}$-isopycnal on North Equatorial Undercurrent (NEUC) INT. Shading marks the slope of linear regression for a lag of -3 months (a; NEUC leads oxygen), zero lag (b), and a lag of +3 months (c; oxygen leads NEUC). Negative values of the slope indicate an anticorrelation between NEUC and oxygen; that is, oxygen is low when the NEUC transport is strong. Black contours mark the significant values of the coefficient of determination ( 0.1 interval starting at 0.4$)$. Black line marks mean position of the NEUC.

In summary, NEUC transports and oxygen concentrations along its pathways are anticorrelated on interannual time scales in TRATL01. This is in contrast to the conclusion drawn from observations (Brandt et al., 2010), where a stronger NEUC is associated with higher oxygen concentrations. The results of this section motivates us to four experiments with a conceptual model that are described in the next section.

\subsection{Conceptual Model}

The conceptual model is used to investigated single processes that appear to be active in the observations and/or in TRATL01. These processes potentially impact the NEUC, its variability, and the associated oxygen distribution. In addition to our reference experiment SIM 1, we perform four experiments (SIM 2 and VAR 1-3) with the conceptual model. First, we want to test how a mean recirculation between NEUC and nSEC affect the oxygen concentrations (SIM 2). Furthermore, we calculate the oxygen response for three possible scenarios: (i) a stronger mean NEUC that is associated with enhanced ventilation from the western boundary and, hence, positive oxygen anomalies along the NEUC (VAR 1); (ii) a stronger NEUC due to a stronger recirculation with the nSEC, which is associated with negative oxygen anomalies in the NEUC (VAR 2); (iii) an oxygen variability of the source waters at the western boundary, which is then advected by the unchanged NEUC toward the east (VAR 3). The experiments are based on the conceptual model (equation (3)) with the horizontal eddy diffusivities $k_{x}=k_{y}=800 \mathrm{~m}^{2} / \mathrm{s}$ and the background flow field given by equation (4) with 
Table 3

Overview Over the Different Simulations Performed With the Concecptual Model (Equation (3))

\begin{tabular}{lccc}
\hline Simulation & Flow field & Velocity amplitude & Oxygen at western boundary \\
\hline SIM 1 & Equation (4) & $u_{0}=0.055 \mathrm{~m} / \mathrm{s}$ & $C_{0}=147 \mu \mathrm{mol} / \mathrm{kg}$ \\
SIM 2 & Equation (4) + equation (7) & $u_{0}=u_{1}=0.035 \mathrm{~m} / \mathrm{s}$ & $C_{0}=147 \mu \mathrm{mol} / \mathrm{kg}$ \\
VAR 1 & Equation (4) & $u_{0}=0.055 \mathrm{~m} \mathrm{~s}^{-1}+0.04 \mathrm{~m} / \mathrm{s} \cdot \sin (t)$ & $C_{0}=147 \mu \mathrm{mol} / \mathrm{kg}$ \\
VAR 2 & Equation (4) + equation (7) & $u_{0}=0.035 \mathrm{~m} / \mathrm{s}$, & $C_{0}=147 \mu \mathrm{mol} / \mathrm{kg}$ \\
& & $u_{1}=0.035 \mathrm{~m} / \mathrm{s}+0.025 \mathrm{~m} / \mathrm{s} \cdot \sin (t)$ & $C_{0}=147 \mu \mathrm{mol} / \mathrm{kg}+4 \mu \mathrm{mol} / \mathrm{kg} \cdot \sin (t)$ \\
VAR 3 & Equation (4) & $u_{0}=0.055 \mathrm{~m} / \mathrm{s}$ & \\
\hline
\end{tabular}

$u_{0}=0.055 \mathrm{~m} / \mathrm{s}$. The design and the results of the four experiments are discussed in the following. Table 3 gives an overview over all the simulations.

The discrepancies of the mean state in TRATL01 and observations motivates our first experiment SIM 2. To study the impact of a recirculation between NEUC and nSEC on the oxygen distribution, the following elliptical velocity field is superimposed on the background flow field (equation (4)) centered between the NEUC and nSEC:

$$
\begin{aligned}
& u= \begin{cases}0.5 \cdot u_{1} \cdot \cos \left(\frac{2 \pi \cdot y}{l y}\right) \cdot\left(\cos \left(\frac{2 \pi \cdot x}{l_{x}}\right)-1\right) & \text { if } 0 \leq y \leq \frac{1}{2} l_{y}, \\
0 & \text { else }\end{cases} \\
& v= \begin{cases}0.5 \cdot u_{1} \cdot \frac{l y}{l x} \cdot \sin \left(\frac{2 \pi \cdot y}{l y}\right) \cdot \sin \left(\frac{2 \pi \cdot x}{l_{x}}\right) & \text { if } 0 \leq y \leq \frac{1}{2} l_{y}, \\
0 & \text { else }\end{cases}
\end{aligned}
$$

where $u_{1}$ is the velocity amplitude of the recirculation $\left(u_{1}=u_{0}\right.$ for steady state simulations). In this experiment the recirculation acts to homogenize the horizontal oxygen distribution in the central and eastern basin resulting in lower oxygen concentrations west and in higher oxygen concentrations east of about $20^{\circ} \mathrm{W}$ compared to SIM 1 (Figures 10 and S1). In SIM 2 maximum zonal velocities occur in the center of the basin and not at the western boundary as in SIM 1. This enables the nSEC to advect more oxygen-poor water from the eastern boundary toward the west, which again hampers the eastward advection of oxygen-rich water by the NEUC and results in a strong zonal oxygen gradient west of $35^{\circ} \mathrm{W}$. Simultaneously, east of $35^{\circ} \mathrm{W}$ the recirculation acts to homogenize the oxygen distribution resulting in a weak horizontal oxygen gradient. Consequently, we found lower oxygen concentrations west of $23^{\circ} \mathrm{W}$ and higher oxygen concentration east of it compared to SIM 1 and observations (Figure S1).

The results of SIM 2 suggest that a recirculation between the NEUC and nSEC acts to weaken the oxygen maximum associated with the NEUC. However, the recirculation in SIM 2 also leads to a better ventilation of the basin east of $23^{\circ} \mathrm{W}$ compared to SIM 1 . This may be due to the boundary condition of the conceptual model, which do not allow any flow through the eastern, northern, and southern boundaries. In reality and in TRATL01 the zonal currents are not limited by a box. For example, the nSEC extends further east and can advect oxygen-poor water from east of $10^{\circ} \mathrm{W}$ toward the west, which additionally acts to decrease oxygen concentrations in TRATL01. This mechanism is not captured by the conceptual model.

In the following we are going to discuss three time-varying experiments VAR 1-3 performed with the conceptual model. The time variability is simulated by a simple $\operatorname{sinusoid} A \cdot \sin (t)$, where $A$ is the amplitude and $t$ is the time. The sinusoid in all experiments has a period of 3 years, as this study focuses on the interannual variability of the NEUC.

VAR 1: Experiment VAR 1 is based on SIM 1 (equation (3) combined with flow field defined by equation (4), no recirculation) and simulates oxygen changes associated with a time varying mean flow. Here we superimpose a sinusoid with $A=0.04 \mathrm{~m} / \mathrm{s}$ on the velocity amplitude of the background flow field $\left(u_{0}=0.055 \mathrm{~m} / \mathrm{s}+0.04 \mathrm{~m} / \mathrm{s} \cdot \sin (t)\right.$ in equation (4); Figure 11a).

VAR 2: To study oxygen changes associated with a time-varying recirculation, experiment VAR 2 is based on SIM 2 (equation (3) combined with flow field defind by equation (4) + equation (7), recirculation included). Here a sinusoid with $A=0.025 \mathrm{~m} / \mathrm{s}$ is superimposed on the velocity amplitude of the recirculation $\left(u_{1}=0.035 \mathrm{~m} / \mathrm{s}+0.025 \mathrm{~m} / \mathrm{s} \cdot \sin (t)\right.$ in equation (7); Figure $\left.11 \mathrm{~b}\right)$. 

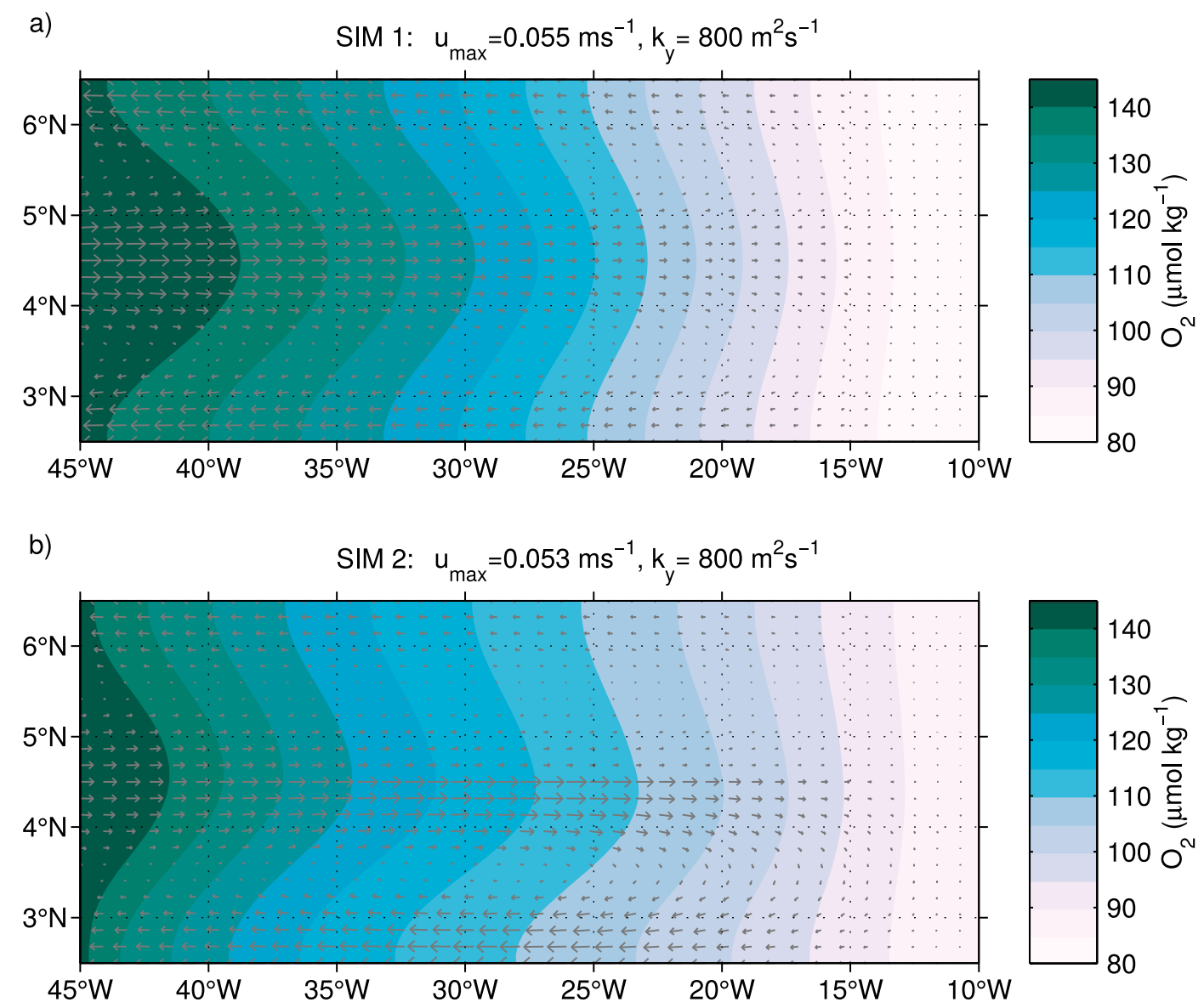

Figure 10. Oxygen distributions (shading) as simulated from equation (3) with $k_{x}=k_{y}=800 \mathrm{~m}^{2} / \mathrm{s} \mathrm{using} \mathrm{(a)} \mathrm{the}$ background flow field (equation (4)) with $u_{0}=0.055 \mathrm{~m} / \mathrm{s}$ and (b) an elliptical flow field (equation (7)) superimposed on the background flow field with $u_{0}=u_{1}=0.035 \mathrm{~m} / \mathrm{s}$. The gray arrows show the velocity fields that have a comparable maximum velocity $\left(u_{\max }\right)$ in (a) and (b).

VAR 3: The last experiment VAR 3 is designed to study oxygen changes associated with time varying oxygen concentrations at the western boundary. VAR 3 is based on SIM 1 (equation (3) combined with flow field defined by equation (4), no recirculation). Here a sinusoid with $A=4 \mu \mathrm{mol} / \mathrm{kg}$ is superimposed on the oxygen source at the western boundary $\left(C_{0}=147 \mu \mathrm{mol} / \mathrm{kg}+4 \mu \mathrm{mol} / \mathrm{kg} \cdot \sin (t)\right)$ while the velocity field is in steady state $\left(u_{0}=0.055 \mathrm{~m} / \mathrm{s}\right.$ in equation (4); Figure 11c).

To analyze the results of experiment VAR 1-3, we investigate the horizontal distribution and magnitude of the simulated oxygen amplitude (oxygen maximum minus oxygen minimum; Figures 11d-11f) during one period of variability ( 3 years). The oxygen amplitude shows where maximum variability occurs in the basin. Additionally, we investigate the phase of the simulated oxygen maximum (Figures 11g-11i). This means we are calculating the time lag between the time of maximum amplitude of the forcing term (Figures 11a-11c) and the time of maximum simulated oxygen concentrations.

In VAR 1 high oxygen amplitudes can be found across the whole basin (Figure 11d). Along the eastward flow east of $40^{\circ} \mathrm{W}$ maximum oxygen concentration occurs within the first 6 months after the velocity is maximum. This supports the suggestion of Brandt et al. (2010) derived for an intermediate jet that a strengthening of the NEUC supplied out of the well-ventilated western boundary region is associated with positive oxygen anomalies. Note that in VAR 1 the oxygen concentrations along the westward return flows become maximum about 1 to 1.5 years after maximum velocities occurs. This means that the oxygen amplitude in the cores of the eastward and the westward currents has a phase shift of 120-180 depending on the longitude ( $180^{\circ}$ near the western boundary, $120^{\circ}$ near the eastern boundary). Consequently, while the oxygen concentrations are high within the NEUC, oxygen is low in the westward return flows and vice versa. In the 

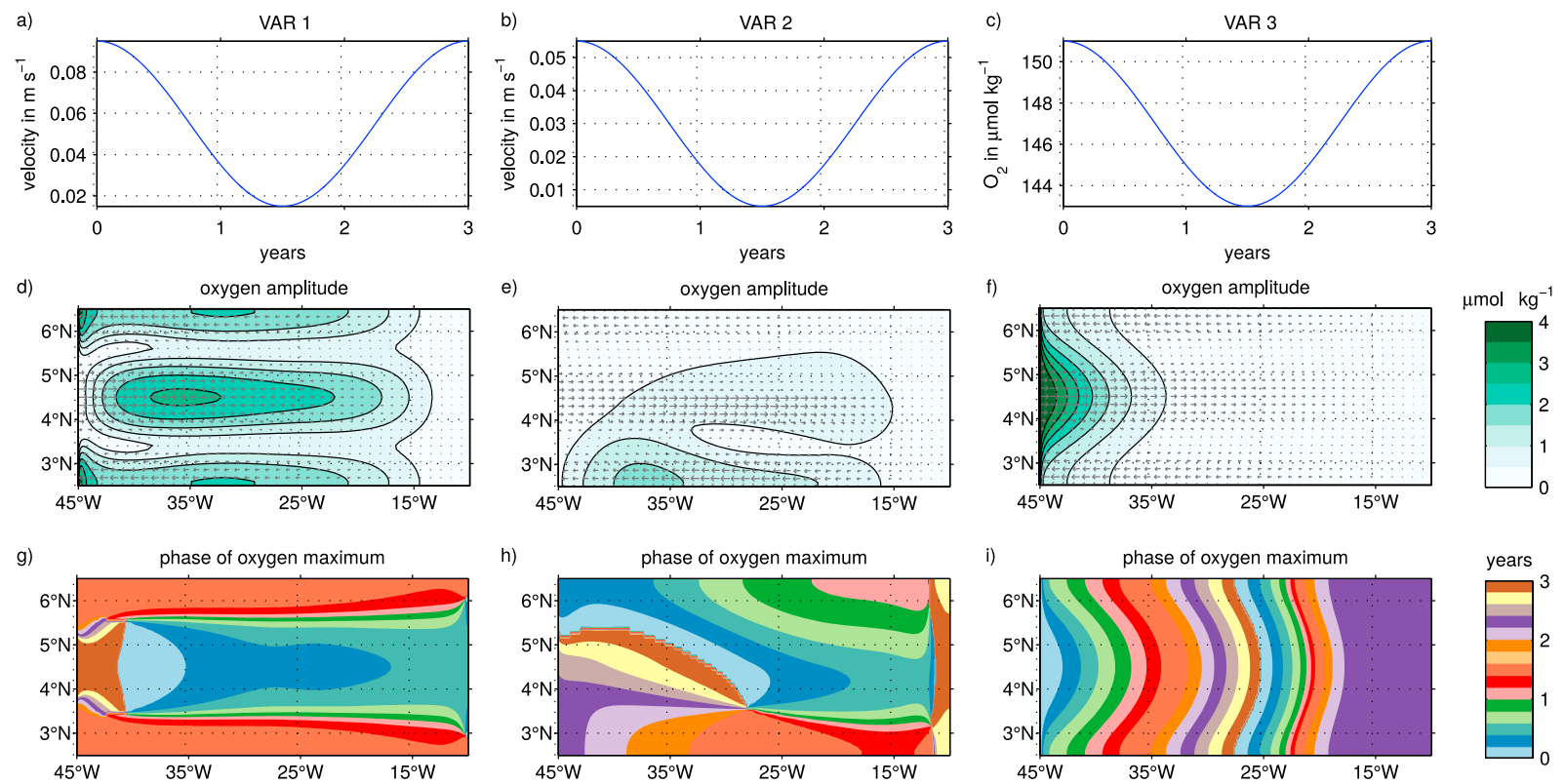

Figure 11. Amplitude of the time-varying forcing (a-c), distribution of oxygen amplitude (shading in d-f), and distribution of phase of oxygen maximum (g-i) simulated with the idealized experiments: time varying background flow field (a, d, and g), time varying recirculation (b, e, and $h$ ), and time varying oxygen at $45^{\circ} \mathrm{W}$ (c, f, and i). Gray arrows in (d)-(f) show the mean horizontal flow field.

eastern basin, the oxygen amplitude is weak (below $0.5 \mu \mathrm{mol} / \mathrm{kg}$ ). This is mainly due to the design of the flow field that has zero flow across the northern, southern, and eastern boundary. In reality and in TRATL01, NEUC waters could exit the model domain toward all model boundaries as shown, for example, in the model simulation of Hüttl-Kabus and Böning (2008).

Experiment VAR 2 can partly explain the results of TRATL01 (Figures 8 and 9). The variable flow here mainly affects the oxygen concentrations of the southern westward return flow west of $25^{\circ} \mathrm{W}$ (Figure 11e). There, maximum oxygen concentrations lag the maximum velocities by 1.5 to 2 years. In other words, within the first 6 months after the velocity amplitude is maximum oxygen concentrations become minimum in the southwestern quarter of the basin. Here a stronger recirculation is associated with negative oxygen anomalies. However, east of $30^{\circ} \mathrm{W}$ along the eastward flow, weak positive oxygen anomalies $(<1 \mu \mathrm{mol} / \mathrm{kg}$ ) occur. When increasing the velocity amplitude of the recirculation and its variability (e.g., $u_{1}=0.07 \mathrm{~m} / \mathrm{s}+0.04 \mathrm{~m} / \mathrm{s} \cdot \sin (t)$ in equation (7)) in VAR 2, oxygen anomalies in the southwest of the basin become more negative and spread northward into the eastward flow during the first 1.5 year after maximum velocities occur (Figure S3). The higher the velocity amplitude of the recirculation and its variability, the higher the negative oxygen anomaly associated with maximum velocities in the southwest of the basin. Note that in VAR 1 oxygen values are minimum along the nSEC during maximum velocities. This suggests that in TRATL01 a combination of both processes, a stronger recirculation between NEUC and nSEC superimposed on a stronger mean flow, might occur. We test the effect of a variable mean flow field that is superimposed by a recirculation by modifying the experiment VAR 2 slightly. Instead of applying the sinusoid to the velocity amplitude of the recirculation in SIM 2, we apply it to the velocity amplitude of the mean flow field (Figure S4). Here similar oxygen pattern as in VAR 1 occur, but the highest variability is confined to the western basin as in VAR 2. In other words, a negative relationship between oxygen concentrations and NEUC strength is only caused by a variability of the recirculation between NEUC and nSEC as simulated in VAR 2 with a strong recirculation (Figure S3). This supports the hypothesis that in TRATL01 stronger (weaker) NEUC and nSEC transports are associated with a higher (lower) recirculation between the currents. A stronger (lower) recirculation is again associated with a stronger (weaker) supply of oxygen-poor water masses from the nSEC to the NEUC.

In VAR 3 the variability of oxygen concentrations at the western boundary shows a minor effect on the basin-wide oxygen distribution (Figures 11c, 11f, and 11i). East of $37^{\circ} \mathrm{W}$ the oxygen amplitude drops below $1 \mu \mathrm{mol} / \mathrm{kg}$, and the weak oxygen maximum east of $30^{\circ} \mathrm{W}$ lags that at the western boundary by over 3 years 
(Figures $11 \mathrm{f}$ and $11 \mathrm{i}$ ). Note that the shading of the phase at about $30^{\circ} \mathrm{W}$ shows values close to zero, but as it is not plausible that the center of the basin is directly impacted by the western boundary, we interpret this as the color bar value plus one period of variability ( 3 years). Consequently, changes of oxygen concentrations about $4 \mu \mathrm{mol} / \mathrm{kg}$ in the source waters of the NEUC are too small to result in noticable signals in the oxygen concentration in the eastern basin on interannual time scales.

In summary the experiments with the conceptual model support our hypothesis that a strong mean recirculation between NEUC and nSEC in TRATL01 can lower the oxygen concentration within the simulated NEUC that, however, is stronger than in observations (SIM 2). Additionally, we find maximum oxygen concentrations along the NEUC during maximum flow (VAR 1), which supports the results of Brandt et al. (2010) derived for an intermediate jet. However, in VAR 1 minimum oxygen concentration occur also along the nSEC during maximum velocities as in TRATL01. Furthermore, a strengthening of the recirculation (VAR 2) leads to negative oxygen anomalies especially in the western basin where the zonal oxygen gradient is high (Figure 11d). This is consistent with the results of TRATL01. The last experiment VAR 3 shows that the effect of oxygen variability at the western boundary on the basin-wide oxygen distribution is negligible on interannual time scales.

\section{Discussion and Conclusion}

In this study we analyze the interannual variability of the NEUC and, in a next step, its impact on oxygen in the ETNA in a state-of-the-art OGCM. As the relationship between changes in current strength and oxygen differs from the one expected from observations, this study further addresses the question which mechanisms might lead to these discrepancies. Our analysis is based on the output of the high-resolution OGCM TRATL01 (Duteil et al., 2014) in combination with an unique data set of 21 ship sections along $23^{\circ} \mathrm{W}$ and a conceptual model simulating an eastward current and its westward return flow with an oxygen source at the western boundary (Brandt et al., 2010).

In observations and in TRATL01, the NEUC is associated with a local oxygen maximum. Although the NEUC in TRATL01 is much stronger than in observations, its associated oxygen maximum is much weaker (Figure 2). The correct representation of oxygen concentrations and their variability in the eastern tropical oceans still proves a challenge for current generation ocean and climate models (e.g., Cabré et al., 2015; Oschlies et al., 2018, 2017). This study suggests that a stronger than observed recirculation between the NEUC and the nSEC in TRATL01 contributes to the model bias in the NEUC region. The experiment SIM 2 performed with the conceptual model supports this hypothesis. In SIM 2 a recirculation between the NEUC and nSEC is superimposed on the background flow field. The results generally show a stronger eastward flow and lower oxygen concentrations west of $23^{\circ} \mathrm{W}$.

Despite our large data set of 21 ship sections, the observations are still too sparse to detect a seasonal signal or long-term variability of the NEUC. The NEUC is a weak current, and in ship sections it is likely obscured by mesoscale activity (e.g., Weisberg \& Weingartner, 1988) and interannual variability (Hüttl-Kabus \& Böning, 2008; Goes et al., 2013) present in the tropical Atlantic .

TRATL01 simulates a seasonal to interannual variability of the NEUC that agrees in general with previous studies (Hüttl-Kabus \& Böning, 2008; Goes et al., 2013) although the mean NEUC transport in TRATL01 is stronger compared to most observation (e.g., Brandt et al., 2006; Bourlès et al., 2002, 1999; Schott et al., 2003; Urbano et al., 2008). The interannual variability of the NEUC in TRATL01 is linked to the AMM (Figure 6). We find an anticorrelation between the NEUC and the AMM index, which is in good agreement with Goes et al. (2013). Our results suggest that the anomalous wind pattern associated with the AMM can hamper or amplify the seasonal cycle of the NEUC. Different mechanisms can potentially impact the NEUC transport. Previous studies suggest that the NEUC might be pulled by the upwelling in the Guinea Dome and along the northwest African coast (Furue et al., 2007, 2009; McCreary et al., 2002). In this study we find that the NEUC strength is related to the anomalous wind stress curl above the ETNA (Figure 5). This wind stress curl anomaly impacts the seasonal shoaling of isopycnals in the eastern equatorial basin (Burmeister et al., 2016; Foltz \& McPhaden, 2010a), which again might impact the seasonal cycle of the NEUC. Additionally, there might be direct wind curl-driven recirculations as suggested by the Sverdrup stream function (contours in Figure 5b). Furthermore, a composite analysis of wind stress suggests enhanced (reduced) coastal upwelling by alongshore winds off Northwest Africa during a strong (weak) NEUC, which would support that the 
NEUC is additionally pulled by coastal upwelling (Figure 6). Another process that might impact the NEUC strength is the Eliassen-Palm flux of TIWs (Jochum \& Malanotte-Rizzoli, 2004). Perez et al. (2012) found that years of high (low) TIW activity are associated with a strong (weak) wind stress curl along $5^{\circ} \mathrm{N}$. We find a strong (weak) wind stress curl during years of strong (weak) NEUC flow. This indicates that anomalous TIW activity might also contribute to interannual NEUC variability.

In contrast to our expectations that a stronger NEUC flow is associated with positive oxygen anomalies along its pathway, we find an inverse relationship of both quantities on interannual time scales in TRATL01 (Figures 8 and 9). Again, a too strong recirculation between the NEUC and the nSEC in TRATL01 can explain the reverse relationship between oxygen and NEUC transports. A stronger recirculation supplies more oxygen-poor water masses from the nSEC into the NEUC. The NEUC in turn transports less oxygen even though it is stronger. In TRATL01 the interannual variability of respiration is too small to have an effect on oxygen, which is consistent with previous studies (Montes et al., 2014; Vergara et al., 2016; Pozo Buil \& Di Lorenzo, 2017; Yang et al., 2017). The large-scale wind pattern associated with the AMM affects not only the NEUC but also the general wind-driven circulation in the tropical Atlantic (Figure 5). Consequently, we find basin-wide oxygen anomalies apart from those associated with the NEUC variability (Figure 8).

We performed three further experiments (VAR 1-3) with the conceptual model to investigate oxygen changes associated with a time varying mean flow (VAR 1), a time varying recirculation (VAR 2), or a time varying oxygen source at the western boundary (VAR 3). In VAR 1 maximum eastward velocities are associated with maximum oxygen concentrations and maximum westward velocities with minimum oxygen concentrations. The highest oxygen variability occurs along the cores of the eastward and westward currents. In VAR 2 highest oxygen variability occurs in the western basin where the oxygen gradient is strongest. This supports our hypothesis that enhanced recirculation between the NEUC and nSEC results in an anticorrelation between NEUC strength and oxygen within the NEUC in TRATL01. The results of VAR 3 suggest that the effect of interannual oxygen variability at the western boundary is of minor importance for the basin-wide oxygen distribution (Figure 11).

The combined results of our analysis allow us to draw the following conclusions: The impact of NEUC interannual variability on the oxygen distribution in the tropical North Atlantic depends on the processes dominating the variability. If a strengthening of the NEUC is associated with a higher ventilation from the western boundary, it will advect more oxygen-rich waters toward the eastern basin. If a strengthening of the NEUC is associated with a stronger recirculation between the NEUC and the nSEC, for example, due to higher TIW activity or directly wind driven, it is advecting less oxygen toward the east. If both processes occur simultaneously, the recirculation will act to damp the effect on oxygen of a stronger NEUC mean flow supplied out of the western boundary current.

A general issue emphasized in this study is the connection of the zonal current system in the tropical North Atlantic to the western boundary. This becomes important especially when investigating tracer distributions. While observational studies suggest that the eastward currents in the tropical Atlantic are important supply routes for oxygen toward the east (e.g., Brandt et al., 2015, 2010; Fischer et al., 2008; Stramma et al., 2008), model studies point to the importance of recirculations between the off-equatorial zonal currents and the EUC (Hüttl-Kabus \& Böning, 2008; Jochum \& Malanotte-Rizzoli, 2004). For example, in observations, the lower part of the SEUC seems to be supplied out of the western boundary (Fischer et al., 2008), but models seem not to be able to simulate this connection (Hüttl-Kabus \& Böning, 2008; Jochum \& Malanotte-Rizzoli, 2004). It is hence important to improve the understanding of the connection of the zonal current system with the well-ventilated western boundary region in the tropical Atlantic in both observations and models.

Realistically simulating the narrow-banded zonal current system of the tropical Atlantic still proves a challenge to ocean models. A promising approach to improve its representation in OGCMs is to increase the horizontal and temporal resolution of the wind forcing as done in the new JRA55-do surface data set (Tsujino et al., 2004). Our results show a relationship between the interannual NEUC and wind stress curl variability in TRATL01 (Figure 5), which suggests that the wind forcing plays an important role. A too coarse resolution of the wind forcing might not resolve important wind stress curl patterns, which could lead to an erroneous representation of the zonal current system. Improving the representation of the zonal current system in the tropical oceans in coupled physical and biogeochemical model simulations is crucial to simulate more realistically the mean state and the variability of the oxygen distribution and the OMZs. 


\section{Acronyms}

$\begin{array}{ll}\text { ADCP } & \text { acoustic Doppler current profiler } \\ \text { AMM } & \text { Atlantic meridional mode } \\ \text { CORE } & \text { Coordinated Ocean-Ice Reference Experiments } \\ \text { CTD } & \text { conductivity-temperature-depth } \\ \text { EUC } & \text { Equatorial Undercurrent } \\ \text { GC } & \text { Guinea Current } \\ \text { ITCZ } & \text { Intertropical Convergence Zone } \\ \text { MIMOC } & \text { monthly, isopycnal/mixed-layer ocean climatology } \\ \text { NEC } & \text { North Equatorial Current } \\ \text { (n)NECC } & \text { (northern branch of the) North Equatorial Countercurrent } \\ \text { NEMO } & \text { Nucleus for European Modeling of the Ocean } \\ \text { NEUC } & \text { North Equatorial Undercurrent } \\ \text { NICC } & \text { North Intermediate Countercurrent } \\ \text { ETNA } & \text { Eastern Tropical North Atlantic } \\ \text { NBC } & \text { North Brazil current } \\ \text { OMZ } & \text { oxygen minimum zone } \\ \text { (n)SEC } & \text { (northern branch of the) South Equatorial Current } \\ \text { SEUC } & \text { South Equatorial Undercurrent } \\ \text { SST } & \text { sea surface temperature } \\ \text { TIW } & \text { tropical instability wave }\end{array}$

\section{References}

This study was funded by the Deutsche Forschungsgemeinschaft as part of the Sonderforschungsbereich 754

"Climate-Biogeochemistry Interactions in the Tropical Ocean," through several research cruises with RV LV Atalante, RV Maria S. Merian, RV Meteor, and RV Polarstern, by the project FOR1740 and by the Deutsche Bundesministerium für Bildung und Forschung (BMBF) as part of projects NORDATLANTIK (03F0605B, 03F0443B) and RACE (03F0651B). We thank the captains, crews, scientists, and technical groups involved in the different national and international research cruises to the eastern tropical North Atlantic that contributed to collecting CTD, velocity (and mooring data), and making them freely available. We thank Johannes Hahn and Rebecca Hummels for postprocessing of the recent ship section data. The shipboard data are accessible at https://doi.pangaea.de/ 10.1594/PANGAEA.899052. We thank Sunke Schmidtko, Gregory C. Johnson, John M. Lyman for creating the MIMOC climatology and making it freely available at http://www.pmel.noaa.gov/mimoc/. The model ouput of TRATL01 was published in Duteil et al. (GRL, 2014, doi: $10.1002 / 2013$ GL058888) and is made available on

https://data.geomar.de. We thank one anonymous reviewer for fruitful comments that improved the manuscript. I: Oceanographic Research Papers, 52(1), 99-121. https://doi.org/10.1016/j.dsr.2004.06.015
Ascani, F., Firing, E., Dutrieux, P., McCreary, J. P., \& Ishida, A. (2010). Deep equatorial ocean circulation induced by a forced-dissipated Yanai beam. Journal Physical Oceanography, 40(5), 1118-1142. https://doi.org/10.1175/2010JPO4356.1

Banyte, D., Tanhua, T., Visbeck, M., Wallace, D. W. R., Karstensen, J., Krahmann, G., et al. (2012). Diapycnal diffusivity at the upper boundary of the tropical North Atlantic oxygen minimum zone. Journal of Geophysical Research, 117, C09016. https://doi.org/10.1029/2011JC007762

Böning, C. W., \& Kröger, J. (2005). Seasonal variability of deep currents in the equatorial Atlantic: A model study. Deep Sea Research Part

Bourlès, B., D'Orgeville, M., Eldin, G., Gouriou, Y., Chuchla, R., DuPenhoat, Y., \& Arnault, S. (2002). On the evolution of the thermocline and subthermocline eastward currents in the Equatorial Atlantic. Geophysical Research Letters, 29(16), 1785. https://doi.org/10.1029/2002GL015098

Bourlès, B., Gouriou, Y., \& Chuchla, R. (1999). On the circulation in the upper layer of the western equatorial Atlantic. Journal of Geophysical Research, 104(C9), 21,151-21,170. https://doi.org/10.1029/1999JC900058

Bourlès, B., Molinari, R. L., Johns, E., Wilson, W. D., \& Leaman, K. D. (1999). Upper layer currents in the western tropical North Atlantic (1989-1991). Journal of Geophysical Research, 104(C1), 1361-1375. https://doi.org/10.1029/1998JC900025

Brandt, P., Bange, H. W., Banyte, D., Dengler, M., Didwischus, S. H., Fischer, T., et al. (2015). On the role of circulation and mixing in the ventilation of oxygen minimum zones with a focus on the eastern tropical North Atlantic. Biogeosciences, 12(2), 489-512. https://doi.org/10.5194/bg-12-489-2015

Brandt, P., \& Eden, C. (2005). Annual cycle and interannual variability of the mid-depth tropical Atlantic Ocean. Deep-Sea Research Part I: Oceanographic Research Papers, 52(2), 199-219. https://doi.org/10.1016/j.dsr.2004.03.011

Brandt, P., Hormann, V., Körtzinger, A., Visbeck, M., Krahmann, G., Stramma, L., et al. (2010). Changes in the ventilation of the oxygen minimum zone of the tropical North Atlantic. Journal of Physical Oceanography, 40(8), 1784-1801. https://doi.org/10.1175/ 2010JPO4301.1

Brandt, P., Schott, F. A., Provost, C., Kartavtseff, A., Hormann, V., Bourlès, B., \& Fischer, J. (2006). Circulation in the central equatorial Atlantic: Mean and intraseasonal to seasonal variability. Geophysical Research Letters, 33, L07609. https://doi.org/10.1029/2005GL025498

Burmeister, K., Brandt, P., \& Lübbecke, J. F. (2016). Revisiting the cause of the eastern equatorial Atlantic cold event in 2009. Journal of Geophysical Research: Ocean, 121, 4777-4789. https://doi.org/10.1002/2016JC011719

Cabré, A., Marinov, I., Bernardello, R., \& Bianchi, D. (2015). Oxygen minimum zones in the tropical Pacific across CMIP5 models: Mean state differences and climate change trends. Biogeosciences, 12(18), 5429-5454. https://doi.org/10.5194/bg-12-5429-2015

Carton, J. A., Cao, X., Giese, B. S., \& Da Silva, A. M. (1996). Decadal and interannual SST variability in the tropical Atlantic Ocean. Journal of Physical Oceanography, 26(7), 1165-1175. https://doi.org/10.1175/1520-0485(1996)026<1165:DAISVI>2.0.CO;2

Chang, P., Saravanan, R., Ji, L., \& Hegerl, G. C. (2000). The effect of local sea surface temperatures on atmospheric circulation over the tropical Atlantic sector. Journal Climate, 13(13), 2195-2216. https://doi.org/10.1175/1520-0442(2000)013<2195:TEOLSS>2.0.CO;2

Dietze, H., \& Loeptien, U. (2013). Revisiting "nutrient trapping" in global coupled biogeochemical ocean circulation models. Global Biogeochemical Cycles, 27, 265-284. https://doi.org/10.1002/gbc.20029

Duteil, O., Schwarzkopf, F. U, Böning, C. W., \& Oschlies, A. (2014). Major role of the equatorial current system in setting oxygen levels in the eastern tropical Atlantic Ocean: A high-resolution model study. Geophysical Research Letters, 41, 2033-2040. https://doi.org/10.1002/2013GL058888

Eden, C. (2006). Middepth equatorial tracer tongues in a model of the Atlantic Ocean. Journal of Geophysical Research, 111, C12025. https://doi.org/10.1029/2006JC003565

Eden, C., \& Greatbatch, R. J. (2008). Diapycnal mixing by mesoscaleeddies. Ocean Modelling, 23(3-4), 113-120. 
Fiorino, M. (2000). The impact of the satellite observing system on low-frequency temperature variability in the ECMWF and NCEP reanalyses. In Proc. Second WCRP Int. Conf. Reanalyses, pp. 65-68.

Fischer, T., Banyte, D., Brandt, P., Dengler, M., Krahmann, G., Tanhua, T., \& Visbeck, M. (2013). Diapycnal oxygen supply to the tropical North Atlantic oxygen minimum zone. Biogeosciences, 10(7), 5079-5093. https://doi.org/10.5194/bg-10-5079-2013

Fischer, J., Brandt, P., Dengler, M., Müller, M., \& Symonds, D. (2003). Surveying the upper ocean with the ocean surveyor: A new phased array Doppler current profiler. Journal of Atmospheric and Oceanic Technology, 20(5), 742-751. https://doi.org/10.1175/1520-0426(2003) $20<742:$ STUOWT $>2.0 . \mathrm{CO} ; 2$

Fischer, J., Hormann, V., Brandt, P., Schott, F. A., Rabe, B., \& Funk, A. (2008). South Equatorial Undercurrent in the western to central tropical Atlantic. Geophysical Research Letters, 35, L21601. https://doi.org/10.1029/2008GL035753

Foltz, G. R., \& McPhaden, M. J. (2010a). Abrupt equatorial wave-induced cooling of the Atlantic cold tongue in 2009. Geophysical Research Letters, 37, L24605. https://doi.org/10.1029/2010GL045522

Foltz, G. R., \& McPhaden, M. J. (2010b). Interaction between the Atlantic meridional and Nio modes. Geophysical Research Letters, 37, L18604. https://doi.org/10.1029/2010GL044001

Furue, R., McCreary, J. P. Jr, \& Yu, Z. (2009). Dynamics of the Northern Tsuchiya Jet*. Journal of Physical Oceanography, 39(9), $2024-2051$. https://doi.org/10.1175/2009JPO4065.1

Furue, R., McCreary, J. P., Yu, Z., \& Wang, D. (2007). Dynamics of the Southern Tsuchiya Jet. Journal of Physical Oceanography, 37(3), 531-553. https://doi.org/10.1175/JPO3024.1

Goes, M., Goni, G., Hormann, V., \& Perez, R. C. (2013). Variability of the Atlantic off-equatorial eastward currents during 1993-2010 using a synthetic method. Journal of Geophysical Research: Ocean, 118, 3026-3045. https://doi.org/10.1002/jgrc.20186

Griffies, S. M., Biastoch, A., Böning, C., Bryan, F., Danabasoglu, G., Chassignet, E. P., \& Yin, J. (2009). Coordinated Ocean-ice Reference Experiments (COREs). Ocean Modelling, 26(1-2), 1-46. https://doi.org/10.1016/j.ocemod.2008.08.007

Hahn, J., Brandt, P., Greatbatch, R. J., Krahmann, G., \& Körtzinger, A. (2014). Oxygen variance and meridional oxygen supply in the Tropical North East Atlantic oxygen minimum zone. Climate Dynamics, 43(11), 2999-3024. https://doi.org/10.1007/s00382-014-2065-0

Hahn, J., Brandt, P., Schmidtko, S., \& Krahmann, G. (2017). Decadal oxygen change in the eastern tropical North Atlantic. Ocean Science, 13(4), 551-576. https://doi.org/10.5194/os-13-551-2017

He, Y. C., Drange, H., Gao, Y., \& Bentsen, M. (2016). Simulated Atlantic Meridional Overturning Circulation in the 20th century with an ocean model forced by reanalysis-based atmospheric data sets. Ocean Modelling, 100, 31-48. https://doi.org/10.1016/ j.ocemod.2015.12.011

Hsin, Y. C., \& Qiu, B. (2012). Seasonal fluctuations of the surface North Equatorial Countercurrent (NECC) across the Pacific basin. Journal of Geophysical Research, 117, C06001. https://doi.org/10.1029/2011JC007794

Hurrell, J. W., \& Trenberth, K. E. (1998). Difficulties in obtaining reliable temperature trends: Reconciling the surface and satellite microwave sounding unit records. Journal Climate, 11(5), 945-967. https://doi.org/10.1175/1520-0442(1998) 011<0945:DIORTT>2.0.CO;2

Hüttl-Kabus, S., \& Böning, C. W. (2008). Pathways and variability of the off-equatorial undercurrents in the Atlantic Ocean. Journal of Geophysical Research, 113, C10018. https://doi.org/10.1029/2007JC004700

Jochum, M., \& Malanotte-Rizzoli, P. (2004). A new theory for the generation of the equatorial subsurface countercurrents. Journal of Physical Oceanography, 34(4), 755-771. https://doi.org/10.1175/1520-0485(2004)034<0755:ANTFTG >2.0.CO;2

Joyce, T. M., Frankignoul, C., Yang, J., \& Phillips, H. E. (2004). Ocean response and feedback to the SST dipole in the tropical Atlantic. Journal of Physical Oceanography, 34(11), 2525-2540. https://doi.org/10.1175/JPO2640.1

Kamenkovich, I., Berloff, P., \& Pedlosky, J. (2009). Role of eddy forcing in the dynamics of multiple zonal jets in a model of the North Pacific. Journal of Physical Oceanography, 39, 1361-1379. https://doi.org/10.1175/2008JPO4096.1

Karstensen, J., Stramma, L., \& Visbeck, M. (2008). Oxygen minimum zones in the eastern tropical Atlantic and Pacific oceans. Progress in Oceanography, 77(4), 331-350. https://doi.org/10.1016/j.pocean.2007.05.009

Köllner, M., Visbeck, M., Tanhua, T., \& Fischer, T. (2016). Diapycnal diffusivity in the core and oxycline of the tropical North Atlantic oxygen minimum zone. Journal of Marine Systems, 160, 54-63. https://doi.org/10.1016/j.jmarsys.2016.03.012

Kriest, I., Khatiwala, S., \& Oschlies, A. (2010). Towards an assessment of simple global marine biogeochemical models of different complexity. Progress in Oceanography, 86(3-4), 337-360. https://doi.org/10.1016/j.pocean.2010.05.002

Madec, G. (2008). "NEMO Ocean Engine", pp. 27. Paris: Inst. Pierre-Simon Laplace.

Marin, F., Hua, B. L., \& Wacongne, S. (2000). The equatorial thermostad and subsurface countercurrents in the light of the dynamics of atmospheric Hadley cells. Journal of Marine Research, 58(3), 405-437. https://doi.org/10.1357/002224000321511098

Matear, R. J., \& Hirst, A. C. (2003). Long-term changes in dissolved oxygen concentrations in the ocean caused by protracted global warming. Global Biogeochemical Cycles, 17(4), 1125. https://doi.org/10.1029/2002GB001997

Maximenko, N. A., Bang, B., \& Sasaki, H. (2005). Observational evidence of alternating zonal jets in the world ocean. Geophysical Research Letters, 32, L12607. https://doi.org/10.1029/2005GL022728

McCreary, J. P., Lu, P., \& Yu, Z. (2002). Dynamics of the Pacific subsurface countercurrents. Journal of Physical Oceanography, 32, 2379-2404. https://doi.org/10.1175/1520-0485(2002)032<2379:DOTPSC $>2.0 . C O ; 2$

Montes, I., Dewitte, B., Gutknecht, E., Paulmier, A., Dadou, I., Oschlies, A., \& Garcon, V. (2014). High-resolutionmodeling of the Eastern Tropical Pacific oxygenminimumzone: Sensitivity to the tropical oceanic circulation. Journal of Geophysical Research: Oceans, 119, 5515-5532. https://doi.org/10.1002/2014JC009858

Nobre, P., \& Shukla, J. (1996). Variation of sea surface temperature, wind stress, and rainfall over the tropical Atlantic and South America. Journal Climate, 9(10), 2464-2479. https://doi.org/10.1175/1520-0442(1996)009<2464:VOSSTW >2.0.CO;2

Ollitrault, M., \& Colin de Verdière, A. (2014). The ocean general circulation near 1000-m depth. Journal of Physical Oceanography, 44(1), 384-409. https://doi.org/10.1175/JPO-D-13-030.1

Oschlies, A., Brandt, P., Stramma, L., \& Schmidtko, S. (2018). Drivers and mechanisms of ocean deoxygenation. Nature Geoscience, 11(7), 467-473. https://doi.org/10.1038/s41561-018-0152-2

Oschlies, A., Duteil, O., Getzlaff, J., Koeve, W., Landolfi, A., \& Schmidtko, S. (2017). Patterns of deoxygenation: Sensitivity to natural and anthropogenic drivers. Philosophical Transactions of the Royal Society A Mathematical Physical Engineering Sciences, 375, 2102. https://doi.org/10.1098/rsta.2016.0325

Peña-Izquierdo, J., Van Sebille, E., Pelegrí, J. L., Sprintall, J., Mason, E., Llanillo, P. J., \& Machín, F. (2015). Water mass pathways to the North Atlantic oxygen minimum zone. Journal of Geophysical Research: Oceans, 120, 3350-3372. https://doi.org/10.1002/2014JC010557

Perez, R. C., Hormann, V., Lumpkin, R., Brandt, P., Johns, W. E., Hernandez, F., et al. (2014). Mean meridional currents in the central and eastern equatorial Atlantic. Climate Dynamics, 43(11), 2943-2962. https://doi.org/10.1007/s00382-013-1968-5 
Perez, R. C., Lumpkin, R., Johns, W. E., Foltz, G. R., \& Hormann, V. (2012). Interannual variations of Atlantic tropical instability waves. Journal of Geophysical Research, 117, C01001. https://doi.org/10.1029/2011JC007584

Pozo Buil, M., \& Di Lorenzo, E. (2017). Decadal dynamics and predictability of oxygen and subsurface tracers in the California Current System. Geophysical Research Letters, 44, 4204-4213. https://doi.org/10.1002/2017GL072931

Qiu, B., Chen, S., \& Sasaki, H. (2013). Generation of the North Equatorial Undercurrent Jets by triad baroclinic Rossby wave interactions. Journal of Physical Oceanography, 43(12), 2682-2698. https://doi.org/10.1175/JPO-D-13-099.1

Rosell-Fieschi, M., Pelegrí, J. L., \& Gourrion, J. (2015). Zonal jets in the equatorial Atlantic Ocean. Progress in Oceanography, 130, 1-18. https://doi.org/10.1016/j.pocean.2014.08.008

Schmidtko, S., Stramma, L., \& Visbeck, M. (2017). Decline in global oceanic oxygen content during the past five decades. Nature, 542(7641), 335-339. https://doi.org/10.1038/nature21399

Schott, F. A., Dengler, M., Brandt, P., Affler, K., Fischer, J., Bourlès, B., et al. (2003). The zonal currents and transports at 35W in the tropical Atlantic. Geophysical Research Letters, 30(7), 1349. https://doi.org/10.1029/2002GL016849

Schott, F. A., McCreary, J. P. Jr, \& Johnson, G. C. (2004). Shallow Overturning Circulations of the Tropical-Subtropical Oceans. Earth's Climate, 147, 261-304.

Schott, F. A., Stramma, L., \& Fischer, J. (1995). The warm water inflow into the western tropical Atlantic boundary regime , spring 1994 waters of the equatorial circulation. Journal Geophysical Research, 100(C12), 24745-24760. https://doi.org/10.1029/95JC02803

Servain, J. (1991). Simple climatic indices for the tropical Atlantic Ocean and some applications. Journal of Geophysical Research, 96(C8), 15137. https://doi.org/10.1029/91JC01046

Stramma, L., Brandt, P., Schafstall, J., Schott, F., Fischer, J., \& Körtzinger, A. (2008). Oxygen minimum zone in the North Atlantic south and east of the Cape Verde Islands. Journal of Geophysical Research, 113, C04014. https://doi.org/10.1029/2007JC004369

Stramma, L., Hüttl, S., \& Schafstall, J. (2005). Water masses and currents in the upper tropical northeast Atlantic off northwest Africa. Journal of Geophysical Research, 110, C12006. https://doi.org/10.1029/2005JC002939

Stramma, L., Johnson, G. C., Sprintall, J., \& Mohrholz, V. (2008). Expanding oxygen-minimum zones in the tropical oceans. Science, 320(5876), 655-658. https://doi.org/10.1126/science.1153847

Stramma, L., Oschlies, A., \& Schmidtko, S. (2012). Mismatch between observed and modeled trends in dissolved upper-ocean oxygen over the last 50 yr. Biogeosciences, 9(10), 4045-4057. https://doi.org/10.5194/bg-9-4045-2012

Thierry, V., Treguier, A. M., \& Mercier, H. (2004). Numerical study of the annual and semi-annual fluctuations in the deep equatorial Atlantic Ocean. Ocean Modelling, 6(1), 1-30. https://doi.org/10.1016/S1463-5003(02)00054-9

Tsujino, H., Urakawa, S., Nakano, H., Small, R. J., Kim, W. M., Yeager, S. G., et al. (2004). JRA-55 based surface dataset for driving ocean-sea-ice models (JRA55-do). Ocean Modelling, 130, 79-139. https://doi.org/10.1016/j.ocemod.2018.07.002

Urbano, D. F., De Almeida, R. A., \& Nobre, P. (2008). Equatorial undercurrent and North equatorial countercurrent at $38^{\circ}$ W: A new perspective from direct velocity data. Journal of Geophysical Research, 113, C04041. https://doi.org/10.1029/2007JC004215

Vergara, O., Dewitte, B., Montes, I., Garçon, V., Ramos, M., \& Pizarro, O. (2016). Seasonal variability of the oxygen minimum zone off Peru in a high-resolution regional coupled model. Biogeosciences, 13(15), 4389-4410. https://doi.org/10.5194/bg-13-4389-2016

Visbeck, M. (2002). Deep velocity profiling using lowered acoustic Doppler current profilers: Bottom track and inverse solutions. Journal of Atmospheric and Oceanic Technology, 19(5), 794-807. https://doi.org/10.1175/1520-0426(2002)019<0794:DVPULA>2.0.CO;2

Wang, C. (2005). Subthermocline tropical cells and equatorial subsurface countercurrents. Deep Sea Research Part I: Oceanographic Research Papers, 52(1), 123-135. https://doi.org/10.1016/j.dsr.2004.08.009

Weisberg, R. H., \& Weingartner, T. J. (1988). Instability waves in the Equatorial Atlantic Ocean. Journal of Physical Oceanography, 18(11), 1641-1657. https://doi.org/10.1175/1520-0485(1988)018<1641:IWITEA >2.0.CO;2

Xie, S., \& Carton, J. (2004). Tropical Atlantic variability: Patterns, mechanisms, and impacts. Geophysical Monograph Series, 147, 121-142. https://doi.org/10.1029/147GM07

Yang, S., Gruber, N., Long, M. C., \& Vogt, M. (2017). ENSO-driven variability of denitrification and suboxia in the Eastern Tropical Pacific Ocean. Global Biogeochemical Cycles, 31, 1470-1487. https://doi.org/10.1002/2016GB005596 